\title{
Scenario-Based Dynamic Negotiation for the Coordination of Multi-Enterprise Supply Chains under Uncertainty
}

\author{
Kefah Hjaila1 ${ }^{1}$, José M. Laínez-Aguirre ${ }^{2}$,Luis Puigjaner ${ }^{1}$ and Antonio Espuña ${ }^{1 *}$ \\ ${ }^{1}$ Chemical Engineering Department, Universitat Politècnica de Catalunya, ETSEIB., Av. Diagonal 647, 08028 \\ Barcelona, Spain. \\ 2Department of Industrial and Systems Engineering, University at Buffalo, NY, United States. \\ *corresponding author: antonio.espuna@upc.edu
}

\begin{abstract}
A novel Scenario-Based Dynamic Negotiation approach is proposed for the coordination of decentralized Supply Chains under uncertainty. The relation between the involved organizations (client, provider and third parties) and their respective conflicting objectives is captured through a non-zero-sum and non-symmetric roles SBDN negotiation. The client (leader) designs coordination agreements considering the uncertain reaction of the provider (follower) resulting from the uncertain nature of the third parties, which is modeled as a probability of acceptance. Different negotiation scenarios are studied: i) Cooperative, and ii) Non-Cooperative and iii) Standalone cases. The use of the resulting models is illustrated through a case study with different vendors around a "leader" (client) in a decentralized scenario. Although the usual cooperation hypothesis will allow higher overall profit expectations, using the proposed approach it is possible to identify non-Cooperative scenarios with high individual profit expectations which are more likely to be accepted by all partners.
\end{abstract}

Keywords: Decentralized Supply Chain; Tactical planning; Uncertainty management; Competitive management.

\section{INTRODUCTION}

Due to the market dynamics, double marginalization, and the volatility of the market, the enterprises decision-makers have to change their way of managing their Supply chains (SCs). Enterprises in the chemical process industry seek "value preservation" to remain competitive and "value growth" to become more innovative (Grossmann, 2004). Many works in the literature propose different procedures to help decision-makers to optimize their SCs, especially at the tactical level, which is the focus of this paper. These works, briefly discussed below, are devoted to the optimization of the whole system from a centralized perspective. However, holding a large scale SC for one enterprise under a centralized decision-maker may not be feasible, thus collaborating with other enterprises may add value to all participating organizations, so that all can remain competitive in the global volatile market. Such collaboration is hard to develop as it depends on the cooperative behavior of the participants. Furthermore, a complexity arises when considering the different (possibly conflicting) objectives of the organizations involved, since they are really trying to optimize its own benefits without considering the risks associated with the uncertain behavior of the other partners.

From a centralized perspective, Laínez et al. (2009) develop an integrated strategic and tactical flexible MILP model taking into account all possible feasible links and material flows 
among the SC facilities. Amaro and Barbosa-Póvoa (2013) develop a close-loop SC tactical model formulation (MILP), coordinating the direct flows (new products) and the reverse flows (recycled) within a centralized closed-loop perspective where the direct and reverse echelons SCs belong to one organization. Zamarripa et al. (2014) propose a LP tactical model for optimizing multi-site multi-product SC networks, coordinating the different steps through the insurance of the consistency of the supply/demand SC. This work has been expanded later by Hjaila et al. (2016) by integrating third parties' financial perspectives as new elements to be considered in the decision making, thus resulting in different (LP, NLP, MINLP) tactical centralized models.

Typical SCM models focus on the single flow of information biased by the decisionmaker of one organization (centralizing player). However, such information is not sufficient to deal with the new market competitive issues resulting from the presence of other partners, such as coordination/collaboration, negotiations, uncertainty. But, the incorporation of third party decisions should be studied in depth.

All the above described works focus on the overall objective of the system, resulting from the coordination between the various echelons/partners within a global SC centralized perspective, so that the individual objectives are disregarded, although they are essential, especially when SC superstructure is decentralized and different organizations are involved, including third parties with conflicting objectives and uncertain behavior.

The resolution of conflictive goals through negotiations has been slightly covered by the PSE literature. The approaches discussed at the bargaining literature include the use of quantity discounts, minimum commitments, buy backs (returns), penalties, and revenue sharing (Cachon, 2003). It is worth to comment the work by Cao et al. (2013) which suggests a trading method based on "revenue sharing" approach to solve the conflicts between one manufacturer and the various competing retailers under the leading role of the manufacturer. The authors consider the uncertainty of the production and final markets demands; however, in this work the manufacturer provides the initial production plan according to its uncertainty behavior regardless of the uncertain behavior of retailers which can lead to SC disruptions. In order to guarantee some benefits to the follower, Zhao et al. (2013) propose a negotiation method for optimizing a SC manufacturer-retailer network through bi-directional option contracts (call or put). For the call option, the manufacturer must buy a specific amount of products at a specific price while, for the put option the retailer must pay an allowance for the cancellation or refund of an order.

Multi-agent systems have been also proposed for optimizing decentralized SC networks. The work of Cao et al. (2007) develop a Pinch Multi-Agent Genetic Algorithm (PMAGA) for network optimization of water-use at the tactical level where stakeholders cooperate to minimize the total used freshwater. Banaszewski et al. (2013) propose an auction protocol tactical model multi-agent for a Brazilian oil SC to identify the oil products transport plan (types, amounts, allocation). However, the multi-agent-based negotiations are oriented to cooperative situations, in which all participating agents cooperate towards a common objective function. This approach disregards individual objectives and their uncertain nature which can affect the performance of the entire system. 
Many works were carried out to optimize decentralized SCs through Game Theory (GT), based on cooperative and non-cooperative cases. For the cooperative case, Hennet and Areda (2008) develop a coordination agreement for a producer and supplier SC through cooperative games based on sharing the backorder costs and capacity reservation in order to maintain supply flows. Zhao et al. (2010) develop a cooperative game model for the optimization of a decentralized manufacturer-retailer SC based on option-contracts under the condition that the manufacturer maximum production coincides with the retailer reserved quantities.

Whereas individual goals through non-cooperative SCs have been studied so far, the proposed approach is based on very simplified SC structures such as in the work of Li et al. (2013). They propose a coordination contract agreement based on "shortage penalty" between one supplier and one buyer (no external markets), so that the follower is obliged to sell which gives a high dominance to the leader. Yue and You (2014) consider more complex structures, in which different competing suppliers and retailers participate. They meet the competition between the different suppliers and retailers through cooperative games based on Nash Equilibrium, while the interactions between the manufacturer and the suppliers/retailers are modeled as non-cooperative Stackelberg games. However, as a cooperative play, competitive suppliers are considered obliged to sell to the manufacturer disregarding the competition among different customers. This gives again a dominant leadership to the customer. Furthermore, in the proposed non-cooperative Stackelberg game, the supplier SC model has been simplified (as LP) in order to be represented as constraints in the manufacturer optimization model (bi-level model), which cannot be resolved if the supplier SC model is a non-convex MINLP (Colson et al. 2007). This approach would require the use of non-realistic linearizing simplifications if the supplier SC should consider aspects like pricing policies, re-design decisions, etc. Moreover, the uncertain behaviors of the followers SCs (suppliers and retailers) are not considered by the leader.

In summary, most of the literature about decentralized SCs tactical decision-making, either for cooperative or non-cooperative cases, focuses on simple SC networks, where the follower is forced to cooperate with the leader, and/or proposes linearized models to represent the behavior of some of the actors which can lead to losing some practicality. Current negotiation methods based on non-cooperative SCs allow to provide individual decisions based on static cases without addressing the full SC picture, which should include how partners may react, thus resulting in incomplete negotiations, especially when the negotiating partners (and their third parties) are subject to risk as the result of external uncertainty sources. Moreover, none of the literature work on decentralized SCs optimization evaluates the negotiation outcome based on the benefits probabilities in order to help the negotiating partners to make a final decision. Thus, effective negotiations able to incorporate the conflicting goals of all participants (including third parties) in tactical models are needed to improve the overall performance of decentralized SC networks and to avoid SCs disruptions.

Consequently, this paper aims to develop a novel Scenario-Based Dynamic Negotiation method (SBDN) as a tool for decision support to provide the best conditions for coordination 
between independent production-distribution SCs with conflicting objectives within decentralized SC. The use of this approach to support negotiations, taking into account the competition between different suppliers/markets and their uncertain nature, will improve the capacity to identify and manage new win-to-win scenarios, thus expanding the boundaries of the SC of interest. Such expansion covers both customers and providers, with their respective production-distribution SCs, as part of the overall system.

In summary, the objectives of this work can be summarized in the following points:

- To analyze cooperative and non-cooperative decentralized SC through a negotiation oriented approach.

- To incorporate in the system the uncertain nature of the different involved parties, and to summarize it in a single behavioral expression associated with the follower reaction which is considered in the leader SC objective function.

- To represent all the involved partners in a complete production-distribution SCs.

- To propose a decision-support strategy to evaluate the overall outcome, based on the risk behavior and the expected benefits of the partners.

- To represent the variations between the profits scenarios in one single approach through the probability of acceptance.

- To create a generic and flexible enough framework by implementing the resulting strategy, able to be used in real-sized cases of centralized/decentralized SCs with simple/complex structures.

\section{Problem Statement}

The main SC of this work produces several products to final customers using resources from different competing providers. In order to improve its individual profits, the main organization (as a client) may consider to collaborate with other production SCs, which are recognized as independent organizations, with their own competing providers and markets, on the basis of a buying/selling resource which from now on will be considered an "inner component" (Figure 1). Since the value of this inner component is an income for the main provider and a cost for the main client, a conflict of interests arises to identify the inner component flows (physical/economic) along the tactical time horizon in this complex competitive environment. In order to solve this conflict, a coordination compromise is usually proposed, but its negotiation may be complex and may even end without an agreement. 


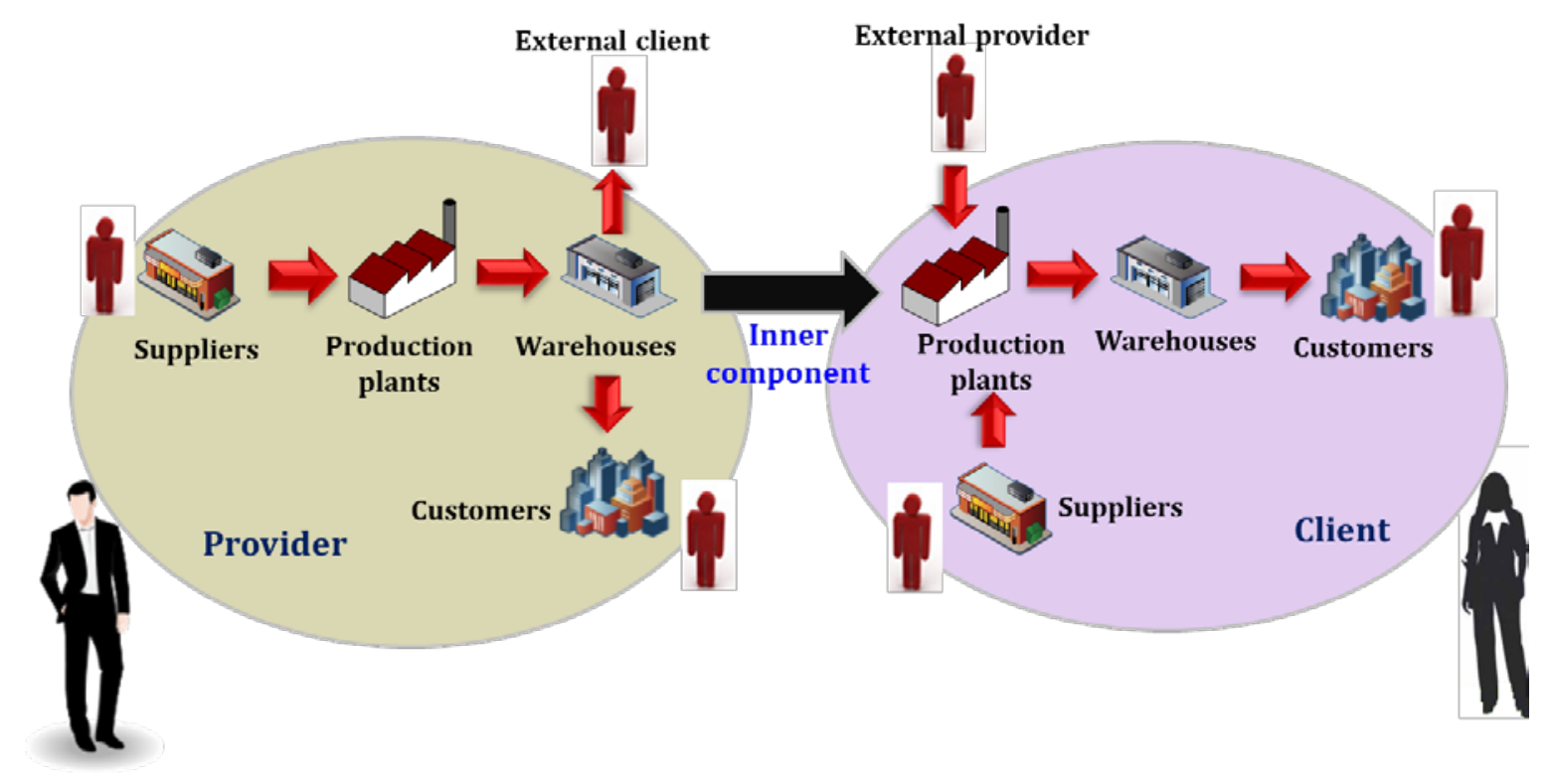

Figure 1- Decentralized SC network and stakeholders

\subsection{SBDN methodology}

In the Scenario Based Dynamic Negotiation approach (SBDN) proposed in this work, the parties in the negotiation are the client and the provider, both participating as productiondistribution SCs in the decentralized SC of interest. The elements of negotiation are the inner component physical flows between their SCs, and obviously its unit transfer price. Our SBDN novel approach is based on building a coordination/collaboration contract, and since any contract is between pairs of stakeholders, two main negotiating partners are considered for signing the contract: the Client and the Provider. The rest of the participants organizations (e.g. suppliers, customers, external providers, external clients, etc.) interacting with the decentralized SC are considered as $3^{\text {rd }}$ parties (Figure 2). However, all $3^{\text {rd }}$ parties participate in the decision-making by means of their price policies as will be explained later.

Based on a non-symmetrical role, the client (as leader) will design a set of coordination contracts based on its best conditions and the provider (as follower) expected response function (Figure 2). This response function is characterized by the uncertain response of the follower $3^{\text {rd }}$ parties to the quantity and the item price offered by the leader at each time slot over the discrete planning time horizon, and will be assessed on the basis of the incomplete knowledge of the follower uncertain behavior and its external conditions (i.e., uncertainty of third parties' behavior). 


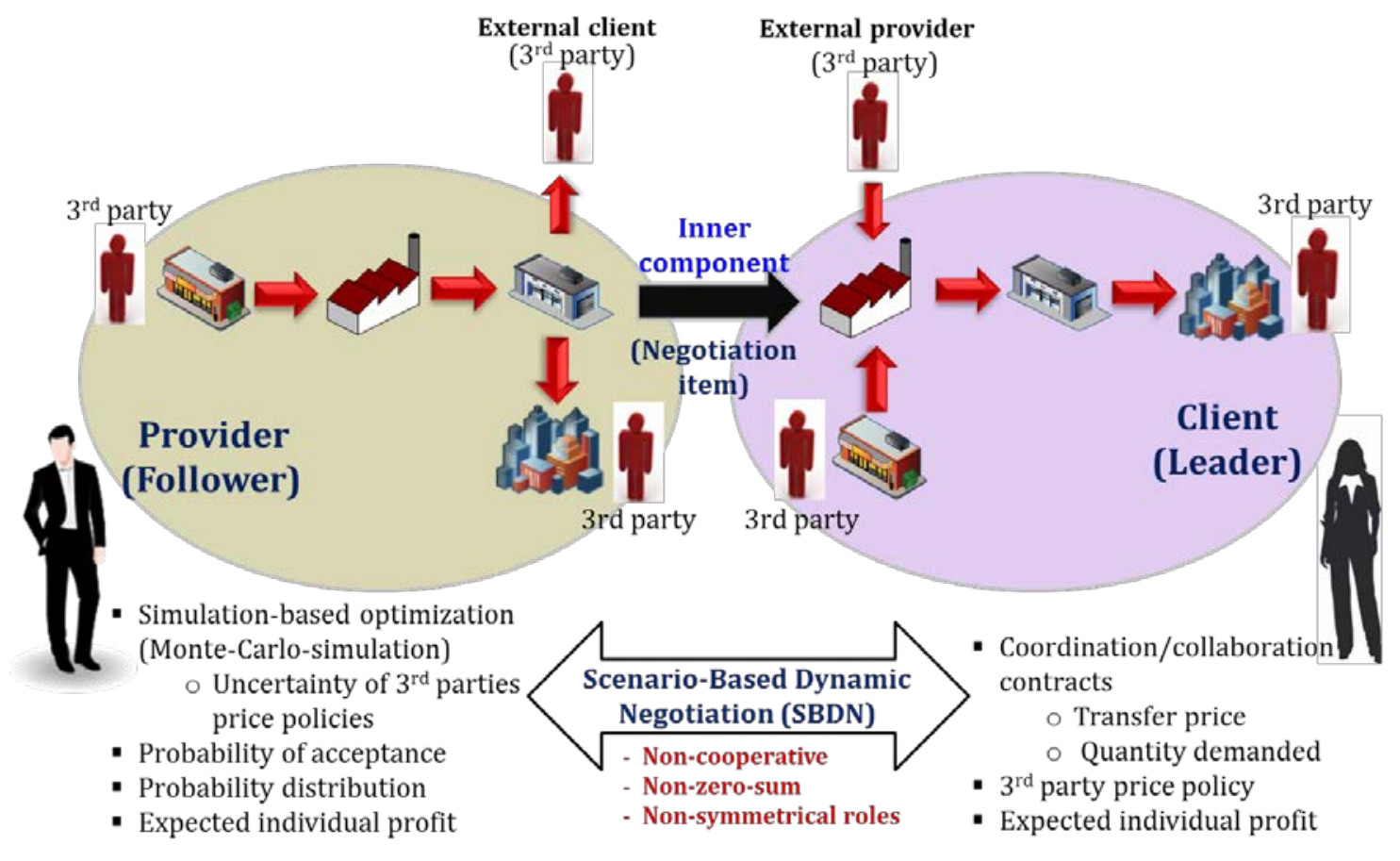

Figure 2-SBDN partners

Figure 3 illustrates the SBDN context. The SBDN depends on many elements: i) the economic context of the participants, especially at the standalone case, ii) the market situation (e.g. prices, competing partners, etc.), iii) the main objectives of each enterprise stakeholder, iv) the quality of the shared information between partners, v) the risk propensity of the main enterprise decision-makers, and finally vi) the probability of acceptance of the follower partner to the decisions made by the leader partner.

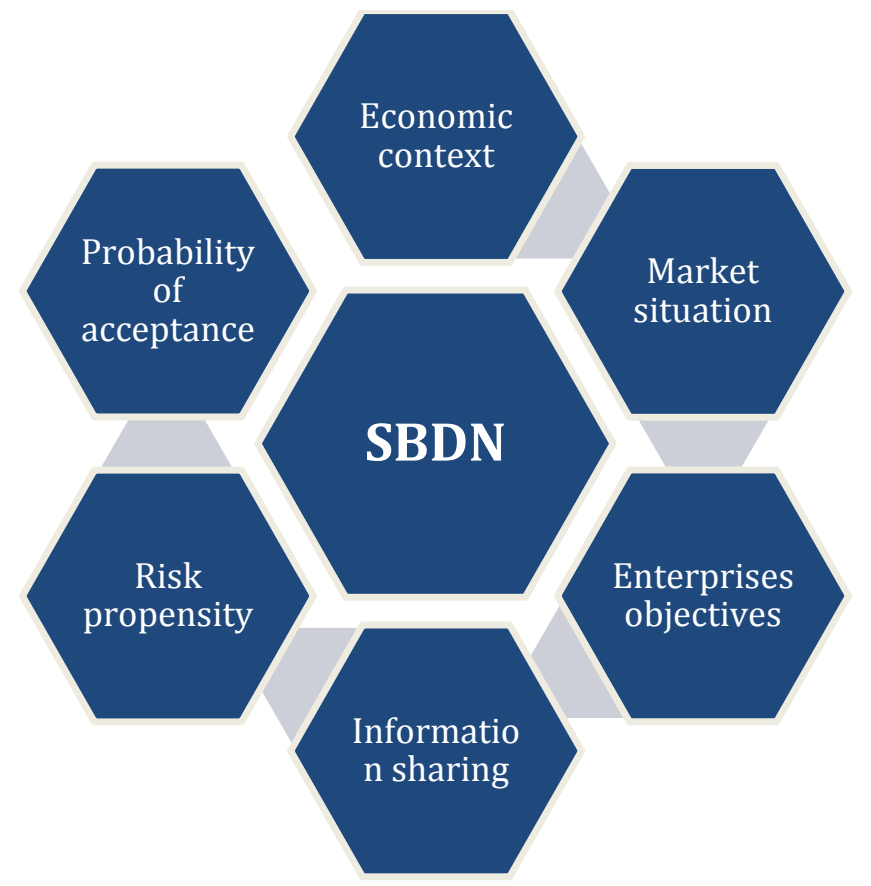


Figure 3-SBDN context

The proposed SBDN methodology can be considered as divided into two main parts (Figure 4): the analysis of negotiation scenarios (identification of the best scenario to be used for negotiating the final agreement), and the preparation of the final coordination/collaboration agreement.

\subsubsection{Negotiation scenarios}

Different negotiation scenarios are analyzed in this work on the basis of three main situations i) Standalone, ii) Cooperative, and iii) Non-Cooperative circumstances (Figure 4).

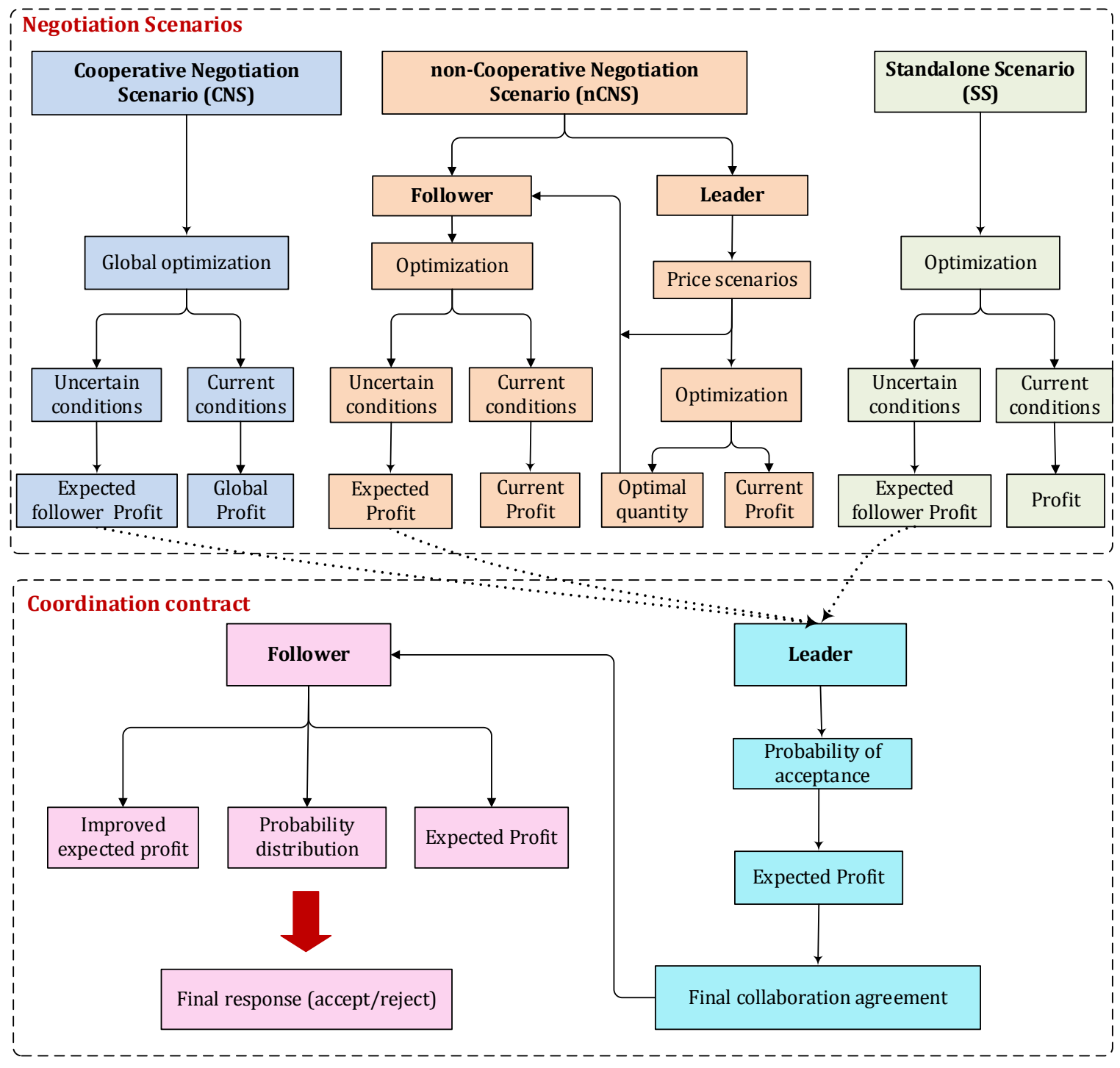

Figure 4- SBDN methodology flowchart

\section{i) Cooperative Negotiation Scenario (CNS):}

Both negotiating parties study the situation under a global perspective, as they were part of a coalition to maximize the overall profit of the SC. This will stablish a second benchmark, in the opposite side. Before starting the negotiation procedures, the logical step 
for the parties is to analyze whether their eventual coordination agreement offers potential benefit expectations (or not).

ii) Non-Cooperative Negotiation Scenario (nCNS)

The leader designs the first play by assessing a set of prices and quantities for the negotiation elements, based on her/his best terms and taking into consideration the competitive prices of the follower SC external markets (based on dynamic "sequential" negotiations). Both parties independently optimize their own SCs taking into consideration the flow of a bargaining (price vs. quantity) over the planning time horizon.

iii) Standalone Scenario (SS):

The negotiating partners optimize their individual profits independently, i.e.: without considering the negotiation step. This scenario will establish individual benchmarks for all methods of negotiation.

\subsubsection{The coordination agreement}

Based on the leader contract offers, both trading partners analyze their expected benefits:

From the leader side:

The benefits of any reduction in the uncertainty associated with the signature of a coordination agreement may be considered. The leader has to forecast to what extent the follower would accept each coordination contract offer by taking into consideration the uncertain reaction associated with the external risk conditions, and the endogenous uncertainty in the follower model. As a result, the probability of acceptance of this agreement by the follower is estimated. Additionally to the non-formal knowledge that each partner has, probably historically accumulated about the rest of partners, this probability of acceptance, may consider set of external feasible scenarios (follower SC) and the subsequent Monte-Carlo sampling approach. Then, the leader may use this probability of acceptance function to calculate the expected profits. The contract proposed by the leader will be that one leading to the most profitable leader's expectations, which in turn will depend on the manner the leader manages uncertainty (risk-seeking, risk-neutral, or risk-averse).

From the follower side:

On the basis of the coordination agreement proposed by the leader, the follower will assess the risks associated with the acceptance or rejection of this cooperation agreement. The evaluation will be based on the probability distribution and cumulative curve of its own expected profits. These probability curves may be also obtained by randomly generating and simulating scenarios through a Monte-Carlo approach (e.g.: assuming normal or any other reasonable probability distribution function). The response of the follower will also depend on how the related organization manages uncertainty (risk-seeking, risk-neutral, or riskaverse). 


\section{Mathematical model}

A generic tactical MINLP has been developed to evaluate different negotiation scenarios. Small changes in the model's constraints allow to introduce different coordination situations which are useful to assess whether a specific proposal is likely to be accepted or rejected by the counterparts.

\subsection{The tactical base model}

The base model is designed to be flexible enough to accept simultaneously all necessary partners with their respective SCs and $3^{\text {rd }}$ parties, which enables them to play different roles (e.g. client for one SC and provider for another SC) within a global SC network. This is done by considering the partner SC's as a set in the mathematical formulation. Accordingly, to represent the negotiation strategy, a set of supply chains $(s c 1, s c 2 \ldots S C)$ is considered linking each SC to its corresponding negotiation partner (follower $F$ or leader $L$ ). Furthermore, the model formulation includes a set of third parties $D$ : leader external providers $(x v)$, follower external clients $(x c)$, suppliers $(s)$, and customers $(m)$. The model includes a set of resources $r$ (RM, final product, energy, etc.), production plants $p l$, and warehouses $w$ as well. A subset $w^{\prime}$ is considered to represent the warehouses belonging to other partner SCs.

Figure 5 illustrates the main interactions between the leader and the follower SCs, including their relations with $3^{\text {rd }}$ parties. The most important variables are illustrated in the figure: $r^{\prime}$ represents the specific resource under negotiation (inner component), which can be purchased from external vendors (xv) and/or sold to external clients (xc). $Q_{r^{\prime}, s c^{\prime}, t}$ represents the quantity of this negotiation item $r^{\prime}$ sent by the follower SC (F) to each production plant $(\mathrm{pl})$ of the leader SC (L) along a discrete planning horizon T, at a transfer price per unit $p_{r^{\prime}, s c^{\prime}}$. $C_{r^{\prime}, w, s c^{\prime}, x c, t}$ and $V_{r^{\prime}, x v, w, s c^{\prime}, t}$ represent the flows of the same kind of resource $\mathrm{r}^{\prime}$ sold to the external clients (xc) and purchased from the external vendors (xv) along the planning horizon T, respectively. The terms $p c_{r^{\prime}, x c, t}$ and $p v_{r^{\prime}, x v, t}$ represent the applicable prices for selling and purchasing to the external clients (xc) and from the external vendors (xv), respectively. 


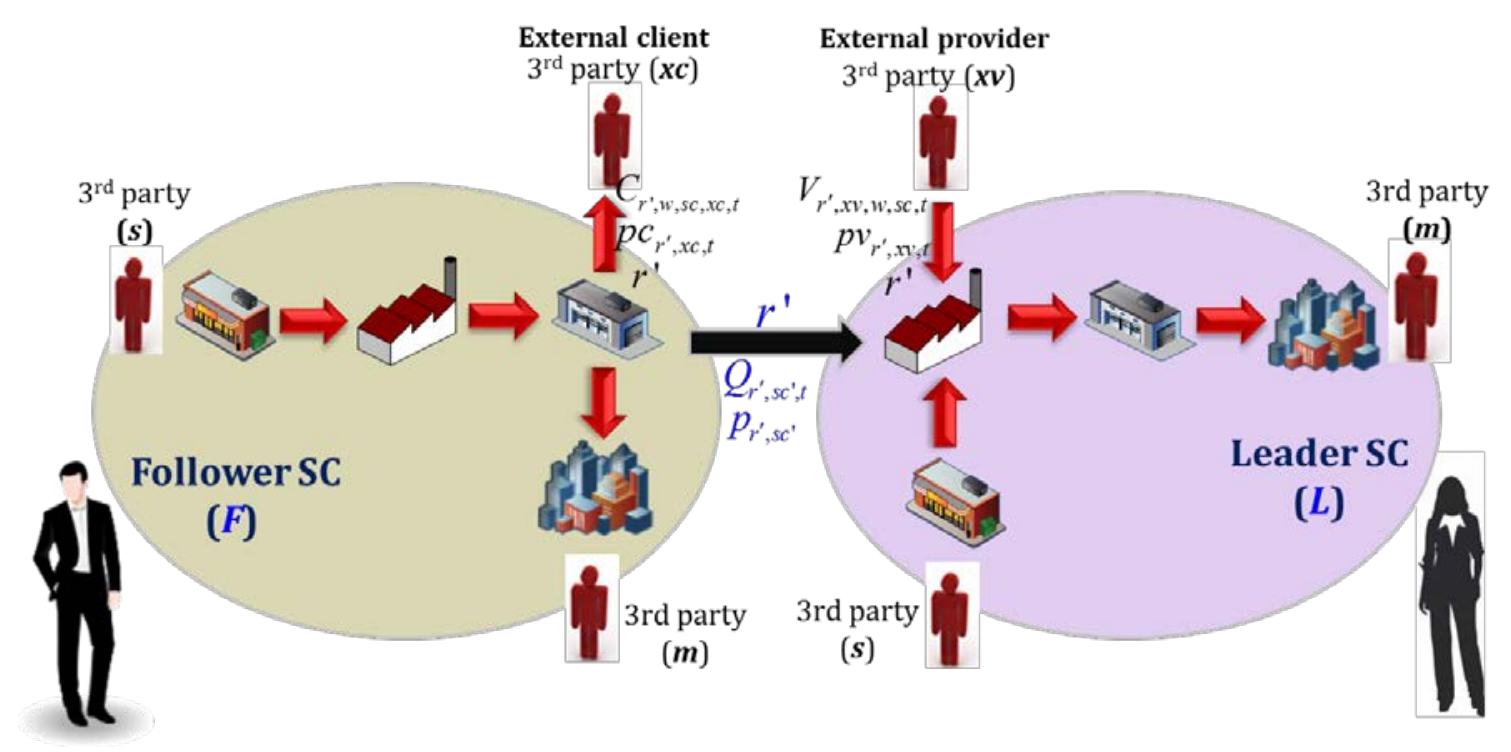

Figure 5- Variable interactions between partners

Unlike other current formulations, the mathematical model associated with the proposed approach gives more flexibility to the negotiating partners, mainly because the follower partners are allowed to accept or reject the outcome of the negotiation: both partners can work independently at the standalone case.

Eq. (1) represents the negotiation item $Q_{r^{\prime}, p l^{\prime}, t}$ demanded by the leader SC manufacturing plants $\left(\mathrm{pl}^{\prime}\right)$. This amount must be more than or equal to the follower SC production levels $F P R D_{r, r^{\prime}, p l, s c^{\prime}, t}$ of $r^{\prime}$ using resource $r$ from the $3^{\text {rd }}$ party (supplier $s$ ) multiplied by the utilized recipe production factor $f_{r, r^{\prime}, s c}$ (assuming linear correlations) minus the amount of $r^{\prime}$ sold to the external clients $(x c)$ over a discrete planning horizon $T$.

$$
\begin{aligned}
& \sum_{p l^{\prime} \in P L} Q L_{r^{\prime}, p l^{\prime}, t} \geq \sum_{\substack{s c^{\prime} \in F \\
s c^{\prime} \in S C}} \sum_{r \in R} \sum_{p l \neq r^{\prime}} F P R D_{r, r^{\prime}, p l, s c^{\prime}, t} \cdot f_{r, r^{\prime}, s c^{\prime}}-\sum_{\substack{s c^{\prime} \in F \\
s c^{\prime} \in S C}} \sum_{x c \in D} \sum_{w \in W} C_{r^{\prime}, w, s c^{\prime}, x c, t} \\
& \forall r^{\prime} \in R ; t \in T
\end{aligned}
$$

The final customers' ( $3^{\text {rd }}$ party $m$ ) receive resources $M K_{r, w, s, m, t}$ from the warehouses $w$ (Eq. 2).

$$
\sum_{w \in W} M K_{r, w, s c, m, t} \leq \operatorname{xdem}_{r, s c, m, t} \quad \forall s C \in S C ; r \in R ; m \in D ; t \in T
$$

Eq. (3) represents the negotiation item ( $r^{\prime}$ ) resource balance at the warehouses of the negotiating partner SCs. $S T_{r^{\prime}, w, s c, t}$ represents the storage levels of $r^{\prime}$ each time period $(t)$; while 
$S T_{r^{\prime}, w, s c, t-1}$ represents the storage levels at time period $(t-1)$ in the warehouses $w$ of any of the

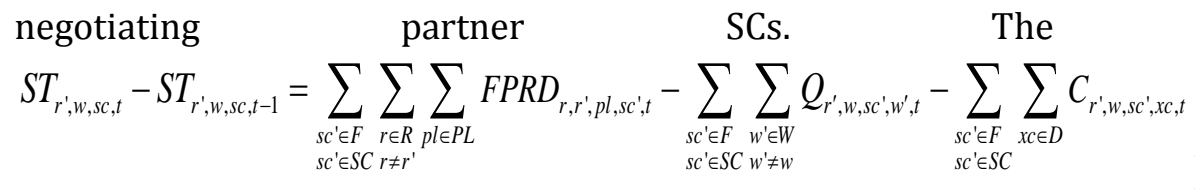
term

the SC belongs to the follower. FPRD $D_{r, r^{\prime}, p l, s c^{\prime}, t}$ represents the follower SC production levels of $r^{\prime}$ from resource $\left(r\right.$ ) purchased from the $3^{\text {rd }}$ party (supplier $s$ ) in the production plants $p l$. $Q_{r^{\prime}, w, s c^{\prime}, w^{\prime}, t}$ represents the flows of $r^{\prime}$ from the follower SC warehouses $(w)$ to the leader SC warehouses $\left(w^{\prime}\right) . C_{r^{\prime}, w, s c^{\prime}, x c, t}$ represents the flows of $\left(r^{\prime}\right)$ from the follower SC warehouses $(w)$ to

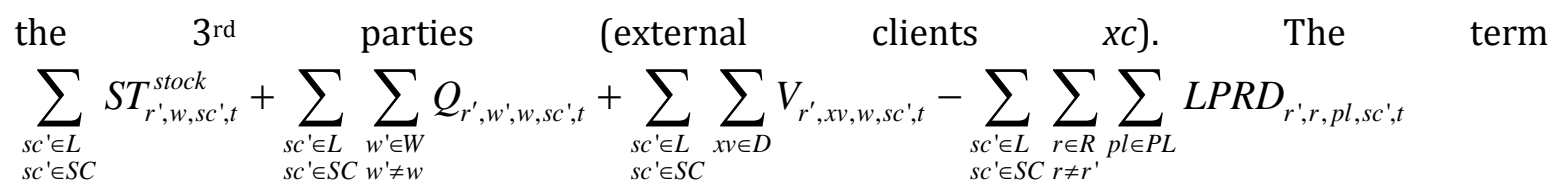
is considered when the SC belongs to the leader partner. $S T_{r^{\prime}, w, s c^{\prime}, t}^{\text {stock }}$ represents the safety stock of $r^{\prime} . Q_{r^{\prime}, w^{\prime}, w, s c^{\prime}, t}$ represents the flows of $\left(r^{\prime}\right)$ from the follower SC warehouses $\left(w^{\prime}\right)$ to the leader SC warehouses $(w)$; while, $V_{r^{\prime}, x v, w, s c^{\prime}, t}$ represents the flows of $\left(r^{\prime}\right)$ from the $3^{\text {rd }}$ parties (external vendors $x v$ ) to the leader SC warehouses $(w)$, and $L P R D_{r^{\prime}, r, p l, s c^{\prime}, t}$ represents the leader production levels of resource $r$ (intermediate product, final product, etc.) from the resource $\left(r^{\prime}\right)$.

Here, it can be noticed the flexibility of the model and its ability to capture all possible SCs with their resources and $3^{\text {rd }}$ parties among a single generic SC tactical model.

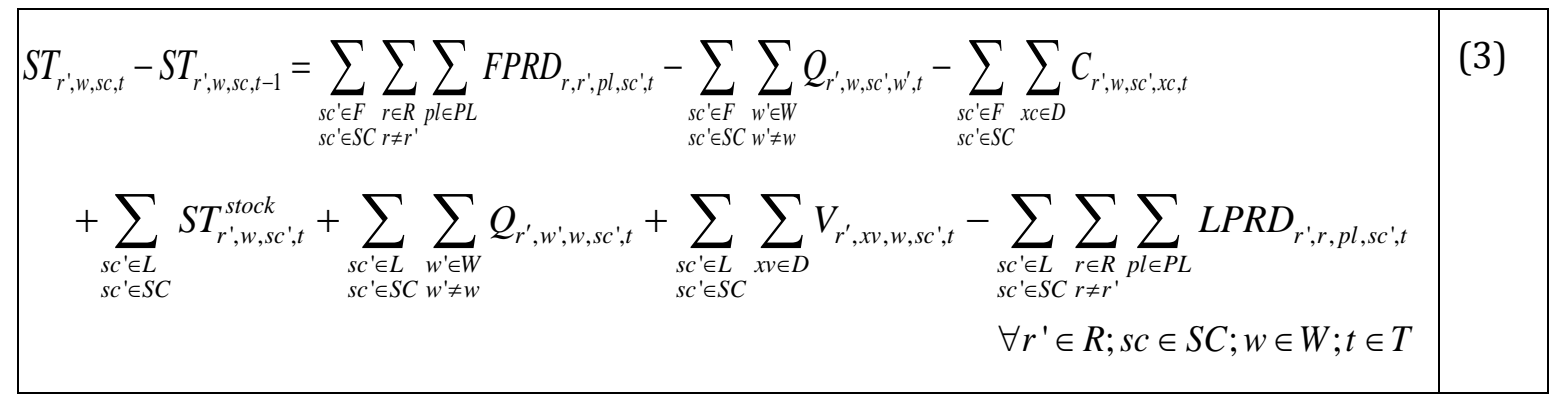

Eqs. (4) and (5) represent the minimum and maximum production and storage capacities, respectively. Similar constraints can be found in Laínez et al. $(2007,2009)$, and Hjaila et al. $(2015,2016)$.

\begin{tabular}{|l|l|}
\hline$P R D_{r, p l, s c, t}^{\min } \leq P R D_{r, p l, s c, t} \leq P R D_{r, p l, s c, t}^{\max }$ & \\
$\forall r \in R ; p l \in P L ; s c \in S C ; t \in T$ & $(4)$ \\
\hline$S T_{r, w, s c, t}^{\min } \leq S T_{r, w, s c, t} \leq S T_{r, w, s c, t}^{\max }$ & $(5)$ \\
\hline
\end{tabular}


$\forall r \in R ; w \in W ; s C \in S C ; t \in T$

The total sales $S A L E_{s c}$ (Eq. 6) include the sales to final customers $m$ plus the sales to the leader SC $(L)$ and to the $3^{\text {rd }}$ party (external client $x c$ ). $r p_{r, s c, m}, P_{r^{\prime}, s c^{\prime}}$, and $p c_{r^{\prime}, x c, t}$ correspond to the retail price of the final product resource, the negotiation item $r^{\prime}$ transfer price, and the retail price of $r^{\prime}$ to the external clients, respectively. The negotiation item value $\sum_{\substack{s c^{\prime} \in F \\ s c^{\prime} \in S C}} \sum_{r^{\prime} \in R} \sum_{t \in T} p_{r^{\prime}, s c^{\prime}} \cdot Q_{r^{\prime}, s c^{\prime}, t}$ and the sales $\sum_{\substack{s c^{\prime} \in F \\ s c^{\prime} \in S C}} \sum_{t \in T} \sum_{r^{\prime} \in R} \sum_{x c \in D} p c_{r^{\prime}, x c, t} \cdot C_{r^{\prime}, s c^{\prime}, x c, t}$ to the $3^{\text {rd }}$ parties (external clients $x c$ ) are considered only when the SC belongs to the follower partner; otherwise, they are zero.

$$
\begin{array}{r}
S A L E_{s c}=\sum_{r \in R} \sum_{m \in D} \sum_{w \in W} \sum_{t \in T} r p_{r, s c, m} \cdot M K_{r, w, s c, m, t}+\sum_{\substack{s c^{\prime} \in F \\
s c^{\prime} \in S C}} \sum_{r^{\prime} \in R} \sum_{t \in T} p_{r^{\prime}, s c^{\prime}} \cdot Q_{r^{\prime}, s c^{\prime}, t}+\sum_{\substack{s c^{\prime} \in F \\
s c^{\prime} \in S C}} \sum_{t \in T} \sum_{r^{\prime} \in R} \sum_{x \in \in D} p c_{r^{\prime}, x c, t} \cdot C_{r^{\prime}, s c^{\prime}, x c} \\
\forall s C \in S C
\end{array}
$$

The SC Cost $\operatorname{COST}_{s c}$ over the considered planning horizon ( $T$ ) is the summation of the external resources purchase from $3^{\text {rd }}$ parties (suppliers $s$ ), production cost, storage cost, distribution cost, the negotiation resource cost, and purchase cost from $3^{\text {rd }}$ parties (external vendors $x v$ ), respectively (Eq. 7). Here can be noticed the conflictive objectives between the negotiating partners: the value $p_{r^{\prime}, s c^{\prime}} \cdot Q_{r^{\prime}, s c^{\prime}, t}$ is considered as sale when the SC belongs to the follower (Eq. 6) and as a cost when the SC belongs to the leader (Eq. 7).

$$
\begin{array}{r}
C O S T_{s c}=C R M_{s c}+C P R_{s c}+C S T_{s c}+C T R_{s c}+\sum_{\substack{s c^{\prime} \in L \\
s c^{\prime} \in S C}} \sum_{t \in T} \sum_{r^{\prime} \in R} p_{r^{\prime}, s c^{\prime}} \cdot Q_{r^{\prime}, s c^{\prime}, t}+\sum_{\substack{s c^{\prime} \in \leq \\
s c^{\prime} \in S C}} \sum_{t \in T} \sum_{r^{\prime} \in R} \sum_{x v \in D} p v_{r^{\prime}, x v, t} \cdot V_{r^{\prime}, x v, s c^{\prime}, t} \\
\forall s C \in S C
\end{array}
$$

As aforementioned, the $3^{\text {rd }}$ parties participate in the decision-making by considering their price policies as variables in the model formulation following the piecewise pricing model proposed by Hjaila et al. (2016). Here, we will explain the integration of the $3^{\text {rd }}$ party (external client $x c$ ) price policy as an example. The rest of the $3^{\text {rd }}$ parties (suppliers $s$, customers $m$, external vendor $x v$ ) price policies are integrated following the same procedure as in Eqs. (8-12). Eqs. (8-12) illustrate the amount $C_{r^{\prime}, s c^{\prime}, x c, t}$ and price $p c_{r^{\prime}, x c, t}$ constraints for each piecewise pricing zone $(n)$. Different price possibilities are offered by the follower according to the quantity demanded each time period $(t)$ at each piecewise pricing zone (n). The binary variable $X_{r^{\prime}, t, n}$ is used to allocate the amounts $C_{r^{\prime}, s c^{\prime}, x c, n, t}$ to its corresponding price $p c_{r^{\prime}, x, t, n}$. Using the same methodology, $p v_{r^{\prime}, x v, t}$ and $V_{r^{\prime}, x v, s c, t}$ are computed from the known $n^{\prime}$ (the number of piecewise price zones of external vendor $x v$ ), $p v_{r^{\prime}, x v, t, n^{\prime}}^{\min } p v_{r^{\prime}, x v, t, n^{\prime}}^{\max }, V_{r^{\prime}, x v, s c^{\prime}, n^{\prime}, t}^{\min }$, and $V_{r^{\prime}, x v, s c^{\prime}, n^{\prime}, t}^{\max }$. 


\begin{tabular}{|lr|r|}
\hline$x_{r^{\prime}, t, n} \cdot C_{r^{\prime}, s c^{\prime}, x c, t, n-1}^{\min } \leq C_{r^{\prime}, s c^{\prime}, x, t, n} \leq C_{r^{\prime}, s c^{\prime}, x c, t, n}^{\max } \cdot x_{r^{\prime}, t, n}$ & $\forall r^{\prime} \in R ; s C^{\prime} \in F, n \in N ; x c \in D ; t \in T$ & (8) \\
\hline$x_{r^{\prime}, t, n} \cdot p c_{r^{\prime}, x c, t, n}^{\min } \leq p c_{r^{\prime}, x c, t, n} \leq p c_{r^{\prime}, x c, t, n-1}^{\max } \cdot x_{r^{\prime}, t, n}$ & $\forall r^{\prime} \in R ; x c \in D ; n \in N ; t \in T$ & $(9)$ \\
\hline$p c_{r^{\prime}, x c, t}=\sum_{n \in N} p c_{r^{\prime}, x c, t, n}$ & $\forall r^{\prime} \in R ; x c \in D ; t \in T$ & $(10)$ \\
\hline$C_{r^{\prime}, s c^{\prime}, x c, t}=\sum_{n \in N} C_{r^{\prime}, s c^{\prime}, x c, t, n}$ & $\forall r^{\prime} \in R ; s C^{\prime} \in F ; x c \in D ; t \in T$ & $(11)$ \\
\hline$\sum_{n \in N} x_{r^{\prime}, x c, t, n} \leq 1$ & & \\
\hline
\end{tabular}

The acquisition costs $C R M_{r, s c}$ of the resources $r$ from the $3^{\text {rd }}$ parties (suppliers $s$ ) are calculated as in Eq. (13). $v r m_{r, s, s c, t}$ and $S_{\text {r }} p_{r, s, s c, t}$ correspond to the external resource $r$ prices and amounts along the planning horizon $T$. They also can be computed with the same procedure as in Eqs. (8-12) with the known n" (the number of piecewise price zones at the supplier s), $v r m_{r, s, s c, n^{\prime \prime}, t}^{\min }, v_{r m}^{\max } m_{r, s, s, n^{\prime \prime}, t}, \operatorname{Sup}_{r, s, s c, n^{\prime \prime}, t}^{\min }$, and $\operatorname{Sup}_{r, s, s c, n^{\prime \prime}, t}^{\max }$

$$
C R M_{s c}=\sum_{t \in T} \sum_{r \in R} \sum_{s \in D} v r m_{r, s, s c, t} \cdot \operatorname{Sup}_{r, s, s c, t} \quad \forall s C \in S C
$$

The production cost $C P R_{s c}$ is computed on the basis of the unit production cost uprd $_{r, s c}$ of resource $r$, and, in case the SC belongs to the follower, the unit production cost $u p r d f_{r^{\prime}, s c}$ of producing the negotiation resource $r^{\prime}$ (Eq. 14). $P R D_{r, p l, s c, t}$ and $F P R D_{r^{\prime}, p l, s c^{\prime}, t}$ are the production levels of resource $r$ in each SC and the production levels of ( $r$ ) in the follower SC when the SC corresponds to the follower partner, respectively.

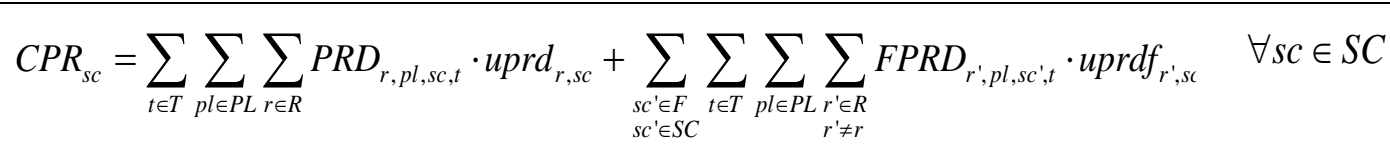

The storage cost $C S T_{s c}$ is computed based on the unit storage costs $u_{s t r} r_{r, w c}$ and ust $r_{r^{\prime}, w, s c}$ of resources $r$ and $r^{\prime}$ in warehouse $w$ at each planning period $t$ (Eq. 15). STR $R_{r, w, s c, t}$ and $S T_{r^{\prime}, w, s c, t}$ are the storage of resources $r$ and $r^{\prime}$ available at time period $t$. 


$$
C S T_{s c}=\sum_{t \in T} \sum_{w \in W} \sum_{r \in R} S T R_{r, w, s c, t} \cdot u s t r_{r, w, s c}+\sum_{t \in T} \sum_{w \in W} \sum_{r^{\prime} \in R} S T_{r^{\prime}, w, s c, t} \cdot u s t_{r^{\prime}, w, s c} \quad \forall s c \in S C
$$

The distribution cost $C T R_{s c}$ is calculated in terms of the travel distances dis $S_{r, s c}$, $\operatorname{dis}_{r, s c}$ and $d i s I_{r^{\prime}, s c^{\prime}}$ of the resources $\left(r\right.$ and $r^{\prime}$ ), and their unit distribution costs (utrs ${ }_{r, s c}$, $u_{t r m_{r, s c}}$, and $u t r I_{r^{\prime}, s c^{\prime}}$ ) (Eq. 16). In this work, it is assumed that the distribution of the negotiation resource $r^{\prime}$ is on the follower partner expenses. Accordingly, when the SC belongs to the leader partner, the last term of Eq. (16) can be eliminated.

$$
\begin{aligned}
& C T R_{s c}=\sum_{r \in R} \sum_{t \in T} \sum_{s \in S} \operatorname{Sup}_{r, s, s c, t} \cdot \text { disS }_{r, s c} \cdot \text { utrs }_{r, s c} \\
&+\sum_{r \in R} \sum_{t \in T} \sum_{m \in M} M K_{r, s c, t} \cdot \operatorname{dis}_{r, s c} \cdot u \operatorname{utrm}_{r, s c}+\sum_{\substack{s c^{\prime} \in F \\
s c^{\prime} \in S C}} \sum_{r^{\prime} \in R} \sum_{t \in T} Q_{r^{\prime}, s c^{\prime}, t} \cdot \text { disI }_{r^{\prime}, s c^{\prime}} \cdot u t r I_{r^{\prime}, s c^{\prime}} \\
& \forall s c \in S C
\end{aligned}
$$

The objective function maximizes the individual SC profit (Eq. 17), which is the difference between the SC sales and cost.

$$
\mathrm{PROF}_{s c}=S A L E_{s c}-\mathrm{COST}_{s c} \quad \forall s c \in S C
$$

The model described in this section is generic and flexible enough to be applied to all kind of SCs, (i.e. cooperative, non-cooperative, standalone). It can cover simple structure to larger scale SCs with their stakeholders and $3^{\text {rd }}$ parties. The base mathematical model is also applicable to centralized SCs by considering. Moreover, it is applicable to standalone SCs by eliminating the interaction terms from the mathematical model $\left(Q_{r^{\prime}, s c^{\prime}, t} \& p_{r^{\prime}, s c^{\prime}}\right)$. The generality of the base model and its application to cooperative SCs stakeholders will be demonstrated in Section 4.

\subsection{Application of negotiation scenarios}

In this section, the MINLP base model is extended/modified according to the different negotiation scenarios to be contemplated:

i) Standalone scenario (SS):

To be more realistic, the negotiating partners have to assess their standalone case to be able to analyze the negotiation outcome (coordination contract). Each negotiating partner, independently, optimizes the related SC profit. Then, the negotiation resource $Q_{r^{\prime}, s c^{\prime}, t}$ in the base model (Eq. 1, 3, 6, 7 and 16) becomes zero.

ii) Cooperative negotiation scenario (CNS): 
The negotiating partners SCs are seen as an integrated SC model seeking the optimization of the overall SC profit (Tprofit) (Eq. 18).

$$
\text { Tprofit }=\sum_{s c \in S C} P R O F_{s c}
$$

\section{iii) Non-cooperative negotiation scenario (nCNS):}

Both negotiating partners pursue the optimization of their individual SC profits, but by considering the negotiation items: quantity $Q_{r^{\prime}, s c^{\prime}, t}$ and price $p_{r^{\prime}, s c^{\prime}}$. Since the value of the negotiation item $\left(p_{r^{\prime}, s c^{\prime}}\right)$ causes a conflict (Eq. 6 and 7), a non-cooperative negotiation is necessary and the outcome is to be documented as a coordination/collaboration contract. Based on non-zero-sum non-symmetric roles, a set of coordination contracts will be prepared by the leader partner. The coordination contract items are: $Q_{r^{\prime}, s c^{\prime}, t}$ flows from the follower SC to each production plant of the leader SC each time period, and the price $p_{r^{\prime}, s c^{\prime}}$.

Both $Q_{r^{\prime}, s c^{\prime}, t}$ and $p_{r^{\prime}, s c^{\prime}}$ are variables in both the leader and the follower tactical optimization models. The non-cooperative non-zero sum nCNS is built on two main steps:

i) The leader optimizes its SC tactical model for a set of coordination/collaboration contract prices $p_{r^{\prime}, s c^{\prime}}^{\text {contract }}$. These prices are offered according to the information that the leader collects about the follower and the external market conditions, and thus they may differ according to the quality of this knowledge. This results in a set of optimal $Q_{r^{\prime}, s c^{\prime}, t}^{\text {contract }}$ which will be considered together with their corresponding prices $p_{r^{\prime}, s c^{\prime}}^{\text {contract }}$ as a set of coordination contracts to be analyzed.

ii) The follower partner optimizes its tactical model considering the set of the coordination contracts obtained from the aforementioned step $\left(Q_{r^{\prime}, s c^{\prime}, t}^{\text {contrat }}\right.$ and $\left.p_{r^{\prime}, s c^{\prime}}^{\text {contr }}\right)$. This can be done by fixing the coordination contract items as parameters in the mathematical model formulation (Eq. 1, 3, 7 and 16). This leads to a reduction in the number of variables, thus mitigating the complexity of the follower SC model.

The above steps result in the individual SC profits plus a set of possible coordination contracts from the leader side. The leader then is facing many coordination contract possibilities to offer. To reduce these contracts, the leader has to anticipate the follower response. To do so, a novel way is proposed based on projecting the uncertain reaction of the follower in the leader decision-making, as illustrated in the next section.

\subsection{Uncertainty management}

As the average is not the efficient way to represent the variations among different values, in this work the follower average of the scenarios profits will not be considered as a measure to evaluate the coordination contracts. Instead, the impact of each profit scenario on 
the decision making of both negotiating partners is considered, and the evaluation of the coordination contracts will be assessed based on the probability of acceptance.

The uncertain reaction of the follower partner resulting from the uncertain behavior of its $3^{\text {rd }}$ parties (suppliers $s$, customers $m$, external client $x v$ ) is projected in the leader SC model as a probability of acceptance. The probability of acceptance prob $_{s c}$ is computed taking into account the expected benefits and the probabilities of occurrence of each generated scenario. In this work a simple ratio between the number of successful scenarios and the total number of scenarios is proposed to calculate the probability of acceptance prob sc $_{\text {(Eq.19). }}$ prob $_{s c}$ is estimated on the basis of the expected profits of the follower SC resulting from the different generated scenarios compared with the expected profits resulting from the standalone case (SS) using the same generated scenarios. In this part, a Monte-Carlo sampling method is used to generate random scenarios of the price policies of the $3^{\text {rd }}$ parties (Eqs. $(6,8-$ 13): $p c_{r^{\prime}, x c, t}, r p_{r, s c, m}$, and $v r m_{r, s, s c, t}$.

$$
\text { prob }_{s c^{\prime}}=\frac{\text { No. of scenarios of improved profits }}{s c^{\prime}} \quad \forall s C^{\prime} \in S C ; s C^{\prime} \in F
$$

The leader expected profit ExPROF sc' is then obtained (Eq. 20) based on the probability of acceptance prob $_{s c^{\prime}}$.

$$
\operatorname{ExPROF}_{s c^{\prime}}=\operatorname{prob}_{s c^{\prime}} \cdot \underset{\text { if the follower accepts }}{P R O F_{s \prime^{\prime}}}+\left(1-\text { prob }_{s c^{\prime}}\right) \cdot \underset{\text { if the follower rejects }}{P R O F_{c^{\prime}}} \quad \forall s c^{\prime} \in S C ; s C^{\prime} \in L
$$

The mathematical model formulation leads to different MINLP models, which can be applied to different configurations of SCs networks with their own competitive $3^{\text {rd }}$ parties. Furthermore, the integration of the $3^{\text {rd }}$ party price polices in the decision making as (Eqs. 6, 7, 8-13), regardless of the added complexity to the model formulation, gives the $3^{\text {rd }}$ parties enough freedom to manage their financial flows, thus allowing them to participate in the decision-making with their uncertain conditions. Subsequently, the equilibrium can be achieved from this negotiation: between the external client $(x c)$ and the leader partner $(L)$ as competing clients to purchase the resource $r^{\prime}$, and between the external vendors $(x v)$ and the follower partner as vendors of the resource $r^{\prime}$. Furthermore, the developed MINLP model constitutes a flexible decision-support tool to cover all types of SCs negotiations (cooperative/non-cooperative), for centralized/decentralized SC networks.

\section{Case study}

The developed MINLP models have been implemented and solved for a case study based on the centralized SC system proposed by Hjaila et al. (2016). The centralized SC is decentralized by assuming a decentralized SC superstructure in order to illustrate the 
proposed approach. Additionally, the planning horizon has been reduced from 10 to 6 time periods and the capacities of the energy generation plants have been increased from $5 \mathrm{MWe}$ to 6MWe in order to enhance the competitive pressure among partners. The negotiating parties are the polystyrene production-distribution organization (as leader) and the energy generation organization (as follower), so the internal energy supplied/demanded is considered as the item to be negotiated (amount and price). Each SC is assumed to also negotiate with other own suppliers and markets (Figure 6), so both follower and leader have the flexibility to accept or reject the offers of their respective counterpart. The equilibrium will be achieved between the competing partners: i) between the polystyrene production SC enterprise stakeholder and the local Grid and external markets of the energy generation SC ( $3^{\text {rd }}$ parties), and ii) between the Local Grid ( $3^{\text {rd }}$ party as external provider to the leader SC) and the energy generation SC enterprise stakeholder.

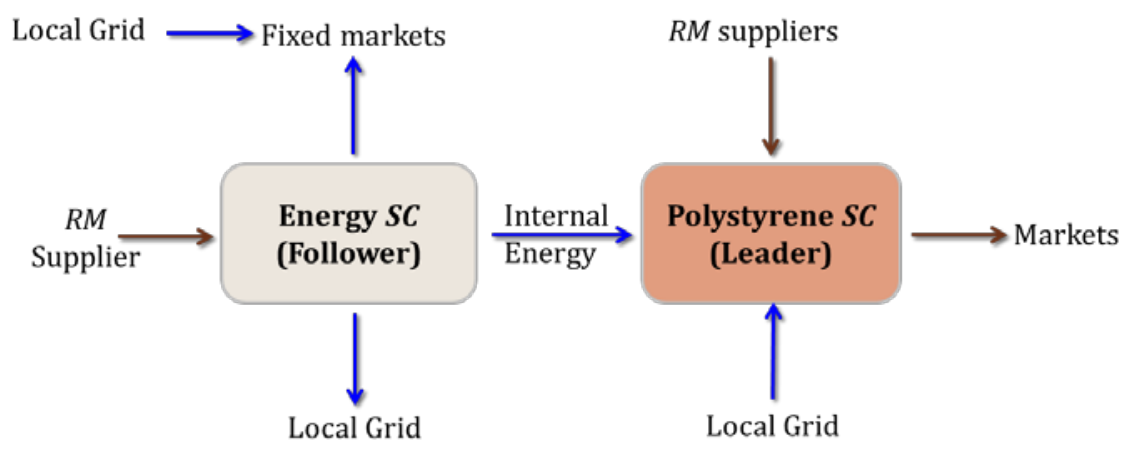

Figure 6- Negotiation partners SCs

The energy generation SC consists of 6 renewable energy generators $(g 1, g 2 \ldots g 6)$ fed by one RM supplier ( $s 1$ ) of 4 alternative competing resources (wood pellets $b 1$, coal $b 2$, petcoke $b 3$, and marc waste $b 4$ ). It is assumed that the energy $R M$ is stored in the energy generation sites if necessary. The energy generation enterprise SC provides energy to the Local Grid and to two external markets (Figure 7). The SC of production-distribution of the polystyrene consists of 3 manufacturing sites ( $p l 1, p l 2$ and $p l 3$ ) producing two different products $(A$ and $B$ ) using 4 alternative resources: $r m 1$ and $r m 2$ to produce product $\mathrm{A}$, and $r m 3$ and $r m 4$ to produce product B. They are provided by 4 competitive suppliers (sup $1, \sup 2$, sup3, and sup4) and the energy is obtained from the Local Grid. The final products $(A$ and $B)$ are stored in 2 warehouses ( $w 1$ and $w 2$ ) to be distributed later to three polystyrene markets ( $m 1, m 2$, and $m 3$ ) (Figure 8). Prices of both SCs external resources follow a piecewise pricing model, as in Hjaila et al. (2016) with an elasticity's price of demand of (-20) for the raw materials of the polystyrene production-distribution SC, and (-25) for the raw materials of the energy generation SC. 


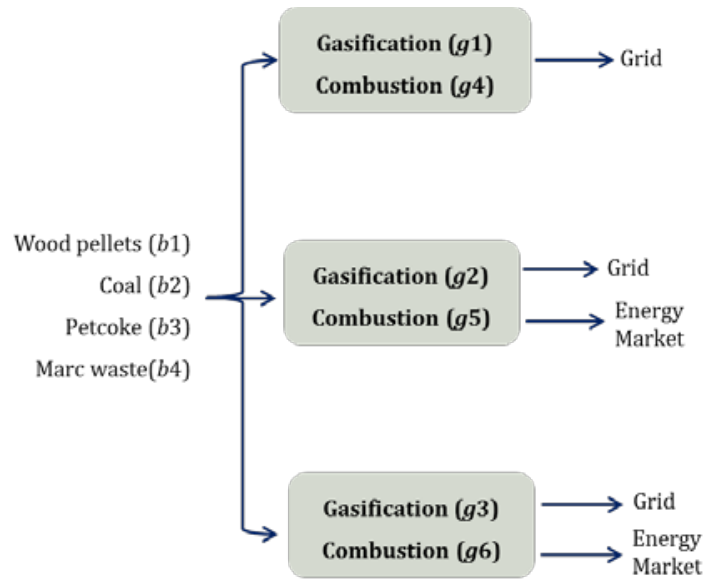

Figure 7- Follower SC (SS)

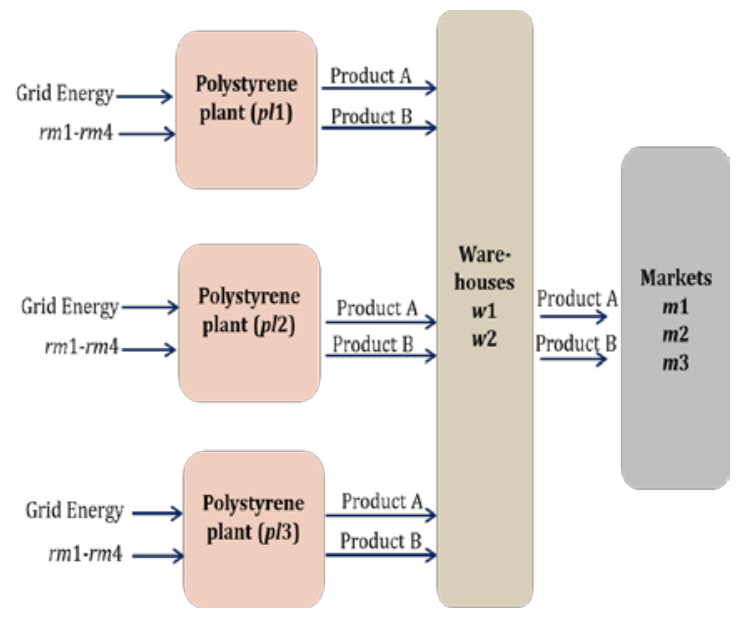

Figure 8- Leader SC (SS)

Table 1 and Table 2 list the distances that the polystyrene RMs travel through the leader SC, and the polystyrene production cost using the different RMs. Table 3 lists the energy generation SC production ratio and cost (energy plants).

Table 1- Distance suppliers/polystyrene production plants (km) (Reference: Hjaila et al., 2016)

\begin{tabular}{cccc}
\hline \multirow{2}{*}{$\begin{array}{c}\text { Polystyrene } \\
\text { SC supplier }\end{array}$} & \multicolumn{3}{c}{ Distance to production plants } \\
\cline { 2 - 4 } & $p l 1$ & $p l 2$ & $p l 3$ \\
\hline sup 1 & 100 & 150 & 145 \\
sup2 & 200 & 120 & 130 \\
sup3 & 110 & 70 & 80 \\
sup4 & 170 & 220 & 215 \\
\hline
\end{tabular}

Table 2- Polystyrene production unit costs

\begin{tabular}{llc}
\hline & & Unit production cost $(€ / \mathrm{kg})$ \\
\hline \multirow{2}{*}{ Product $A$} & $r m 1$ & 0.64 \\
& $r m 2$ & 0.62 \\
\hline \multirow{2}{*}{ Product $B$} & $r m 3$ & 0.58 \\
& $r m 4$ & 0.53 \\
\hline
\end{tabular}

Table 3- Energy generation plants production ratio and cost

\begin{tabular}{ccccc}
\hline & \multicolumn{2}{c}{ Production ratio } & \multicolumn{2}{c}{ Production cost } \\
\hline & $g 1-g 3$ & $g 4-g 6$ & $g 1-g 3$ & $g 4-g 6$ \\
\hline$b 1$ & 0.73 & 1.50 & 0.26 & 0.13 \\
$b 2$ & 2.00 & 2.60 & 0.20 & 0.14 \\
$b 3$ & 0.85 & 1.80 & 0.21 & 0.15 \\
$b 4$ & 0.80 & 2.00 & 0.23 & 0.14 \\
\hline
\end{tabular}

The energy prices and costs to and from the local Grid are given in Table 4 taking into consideration the characteristics of the Spanish public electricity (Ministry of Industry, Energy and Tourism, 2015). These prices vary according to the tariff type and rates in Spain.). 
Table 4- Current external energy prices

\begin{tabular}{lc}
\hline & $\begin{array}{c}\text { Energy price } \\
(€ / \mathrm{kWh})\end{array}$ \\
\hline Energy price to the fixed energy markets & 0.20 \\
Energy price to Local Grid (demand <2GWh) & 0.21 \\
Energy price to Local Grid (2GWh<demand < 4GWh) & 0.20 \\
Energy price to Local Grid (4GWh<demand <6GWh) & 0.19 \\
Local Grid energy price to energy markets & 0.22 \\
Local Grid energy price to Polystyrene SC (demand $>2 \mathrm{GWh})$ & 0.22 \\
Local Grid energy price to Polystyrene SC $(2 \mathrm{GWh}<\mathrm{demand}<4 \mathrm{GWh})$ & 0.21 \\
Local Grid energy price to Polystyrene $\mathrm{SC}(4 \mathrm{GWh}<\mathrm{demand}<8 \mathrm{GWh})$ & 0.20 \\
\hline
\end{tabular}

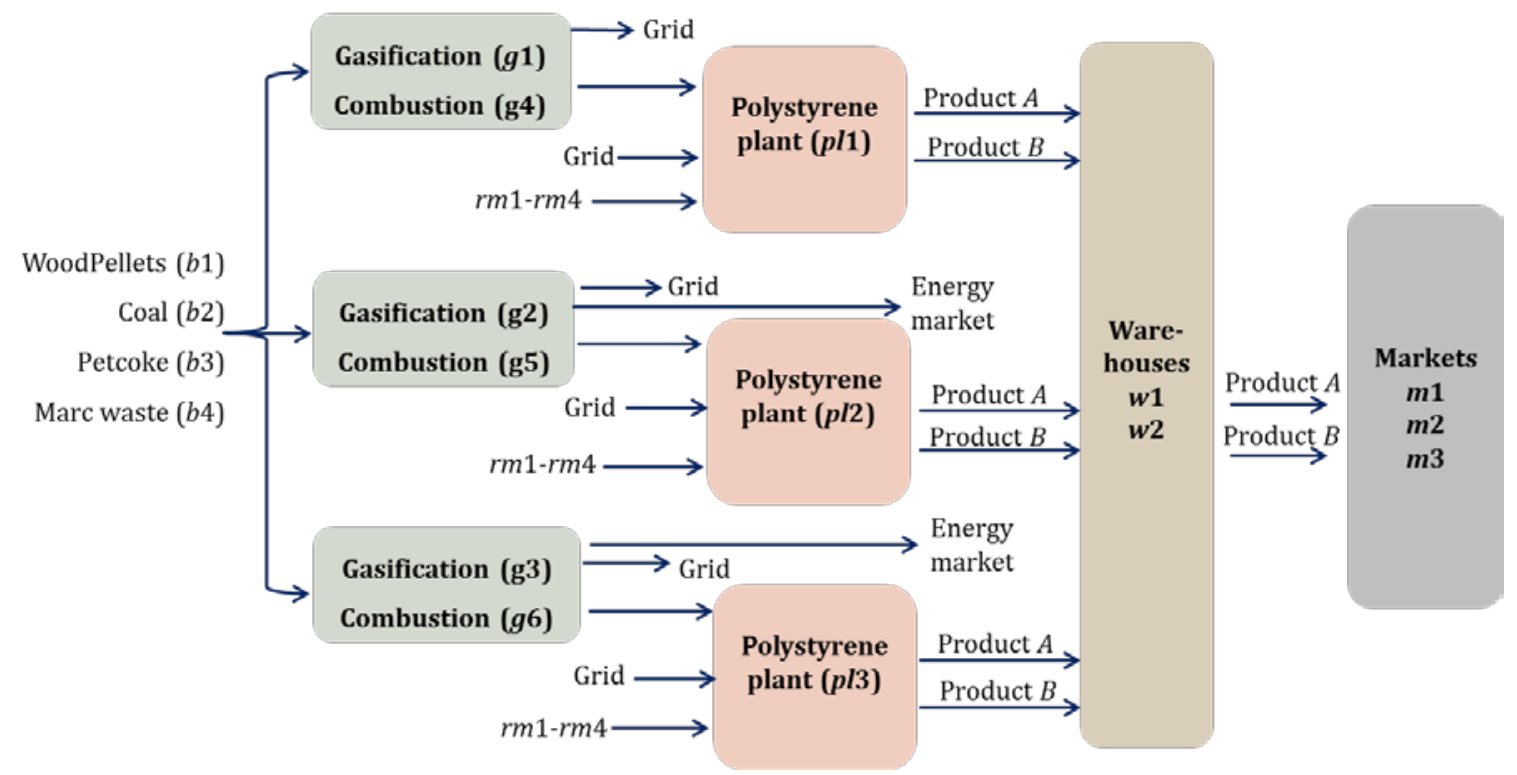

\section{Results and discussion}

Figure 9- Decentralized SC network

As a first step, the MINLP tactical models of both negotiating partners are optimized as standalone cases, so that the standalone (SS) individual profits are obtained. Then, for both CNS and nCNS cases (see Figure 9 Decentralized SC), the negotiation is held to identify the internal energy flows (negotiation item) over the whole planning time horizon. The leader may offer several prices for the internal energy in this case varying from 0.14 to $0.22 € / \mathrm{kWh}$ (contract prices $p_{r^{\prime}, s c^{\prime}}^{\text {contract }}$ in the mathematical model). These prices are estimated based on the electrical energy price variations in Spain during the last ten years. The leader may also offer lower prices, but this would result in the rejection of the contract by the follower partner. So, these offers depend on the knowledge that the leader has about the follower and the $3^{\text {rd }}$ parties price variations (local Grid purchase prices from the follower, local Grid selling price 
to external markets, and the renewable energy price to the external markets). For the CNS and nCNS, the total and individual expected profits are obtained for each energy price offer to be considered.

The proposed SBDN resulted in the different MINLP models for the different proposed cases (Standalone - SS, Cooperative Negotiation - CNS and Non-Cooperative Negotiation nCNS). They have been implemented using the General Algebraic Modeling System GAMS 24.2.3, and solved over the planning time horizon ( 6 time periods; 1000 working hours each) on a Windows 7 computer with an Intel ${ }^{\circledR}$ Core $^{\mathrm{TM}}$ i7-2600 CPU 3.40GHz processor with $16.0 \mathrm{~GB}$ of RAM, using the Global mixed-integer quadratic optimizer "GloMIQO" (Misener \& Floudas, 2013).

The models statistics show that the nCNS mathematical formulation is less complex as it allows to identify better solutions in less computational efforts; $32 \%$ less than the SS and 63\% less than the CNS scenarios, respectively (Table 5).

Table 5- Models statistics

\begin{tabular}{lcccc}
\hline & $\begin{array}{c}\text { Single } \\
\text { equations }\end{array}$ & $\begin{array}{c}\text { Single } \\
\text { variables }\end{array}$ & $\begin{array}{c}\text { Discret } \\
\text { variables }\end{array}$ & CPU (sec) \\
\hline Standalone Scenario (SS) & 2,166 & 2,942 & 306 & 15.6 \\
Cooperative Negotiation Scenario (CNS) & 2,165 & 2,926 & 306 & 31.6 \\
Non-Cooperative Negotiation Scenario (nCNS) & 2,166 & 2,942 & 306 & 11.8 \\
\hline
\end{tabular}

The tactical decisions achieved are the expected RM acquisition, internal product flows and prices (contract terms), and expected production, inventory, and distribution levels for each partner.

In the next subsections, the resulting SC individual and global profits for each coordination contract are discussed, and the effects of the uncertain reaction of the follower on the tactical decisions of the decentralized SC are analyzed, as well as the effects of the follower response on the leader SC tactical and economic decisions.

\subsection{Negotiation Scenarios}

On the one hand, considering a deterministic situation based on the current market energy prices (Table 4), the total and individual SC Profits (nominal) resulting from the different leader coordination contract offers are obtained (Figures $10 \& 11$ ). The purple line represents the SC nominal profits ensuing from the leader SC (Figure 10) and the Follower SC (Figure 11) standalone scenarios (SS); so the negotiation only makes sense when the profits exceed these lines. From the leader side (Figure 10), it seems that the nCNS leads to better solutions than the CNS at all negotiation prices offers, although the CNS leads to higher overall profits (Figure 12). 


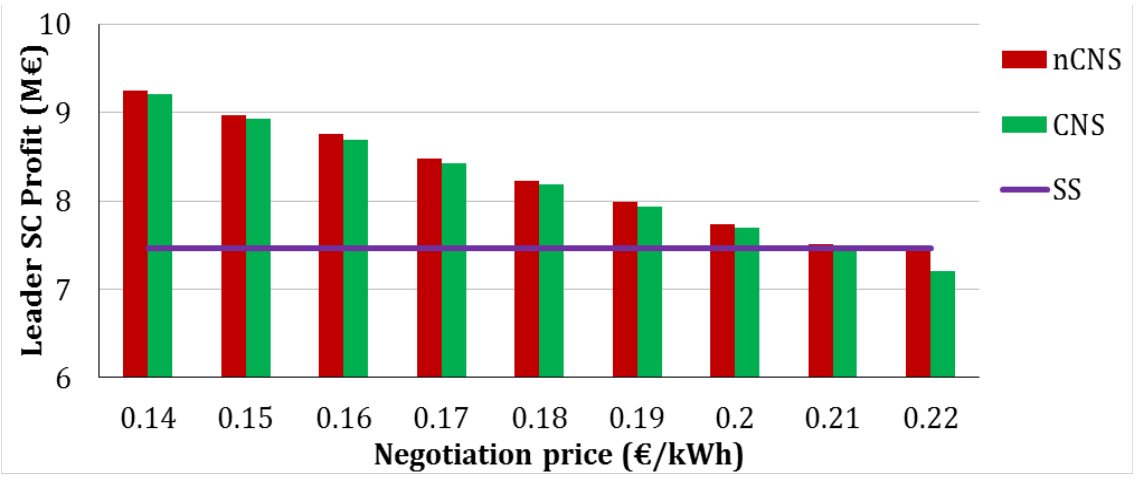

Figure 10- Leader SC nominal profit vs. negotiation price

From the follower side, it is noticed that for negotiation prices above $0.17 € / \mathrm{kWh}$ the CNS would lead to better profits (Figure 12), if the risks associated with its SC uncertain external conditions are not considered.

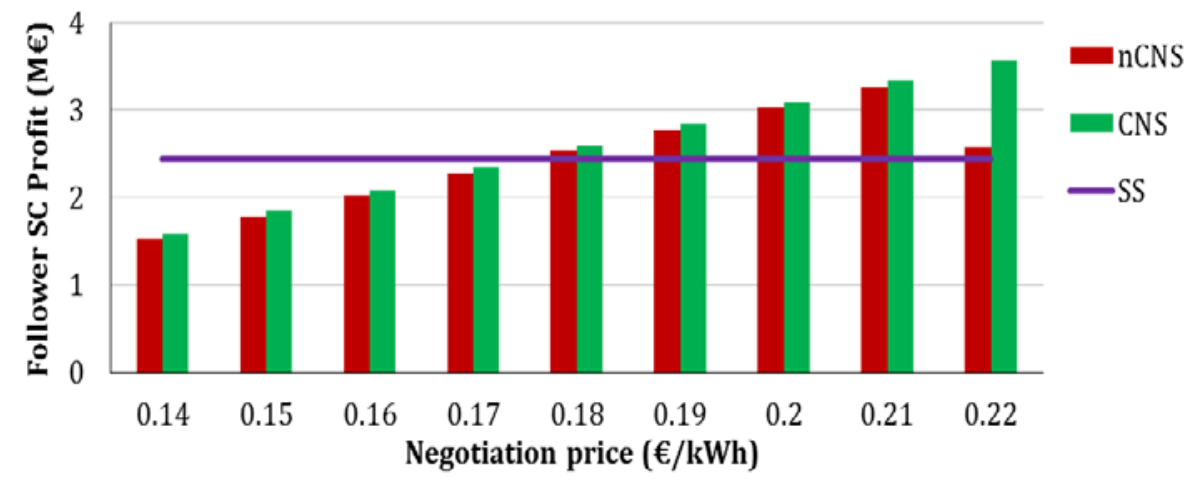

Figure 11- Follower SC Profit vs. negotiation price

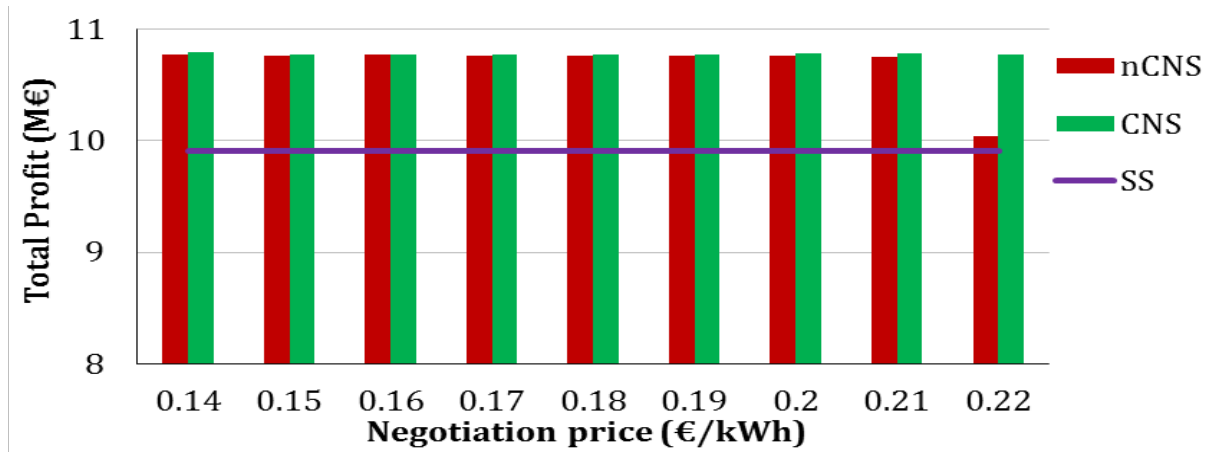

Figure 12- Overall SC Profit

\subsection{Monte-Carlo sampling}

The use of Monte-Carlo sampling as part of the optimization procedure is a practical way to reduce the complexity of the model formulation, by considering a set of realizations of the uncertain variables as representative of the global system behaviour. It helps in obtaining the probability of acceptance of the different offers, the probability distribution of expected profits and the cumulative probability curves. In this case, in order to obtain the probability of acceptance of each of the different contract offers (flows and prices), the proposed MINLP 
tactical model of the follower is solved for each contract offer at the different generated scenarios, in order to obtain each one emulating a realization of the external energy prices of the $3^{\text {rd }}$ parties around the follower SC as follows (Figure 13). Each scenario includes specific random values of:

(a) the local Grid energy price to the external markets (Figure 13a),

(b) the renewable energy price from the follower to local Grid at price zone 1 (Figure 13b),

(c) the renewable energy price from the follower to local Grid at price zone 2 (Figure 13c),

(d) the renewable energy price from the follower to local Grid at price zone 3 (Figure 13d),

(e) the renewable energy price from the follower to the external markets (Figure 13e).

a)

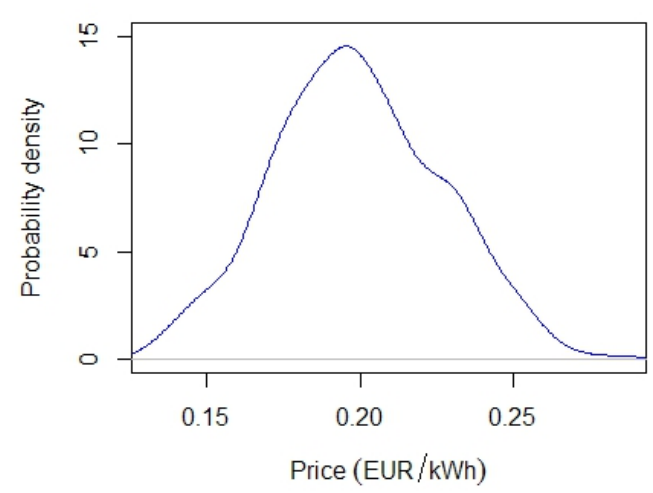

c)

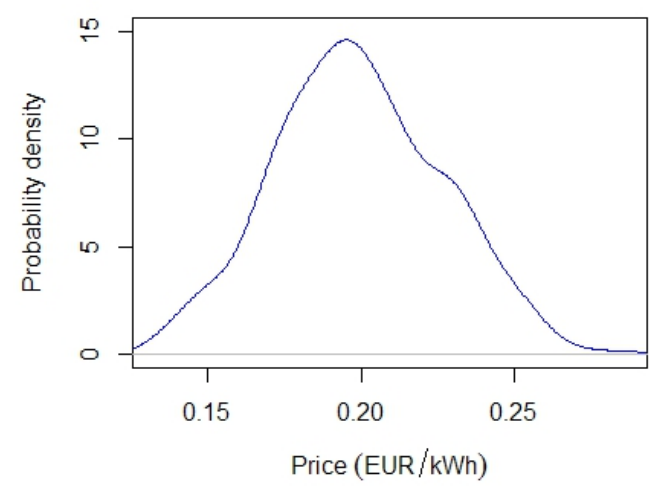

b)

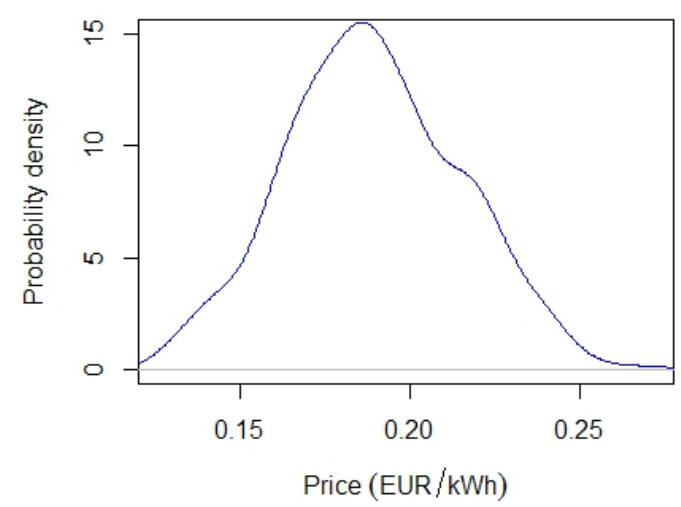

d)

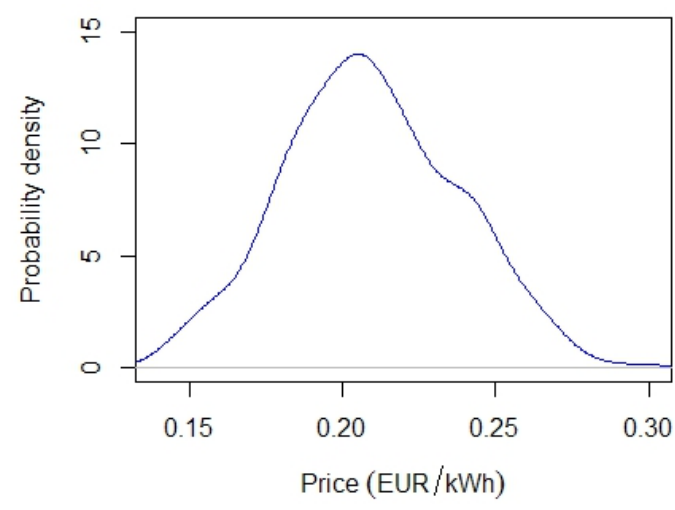




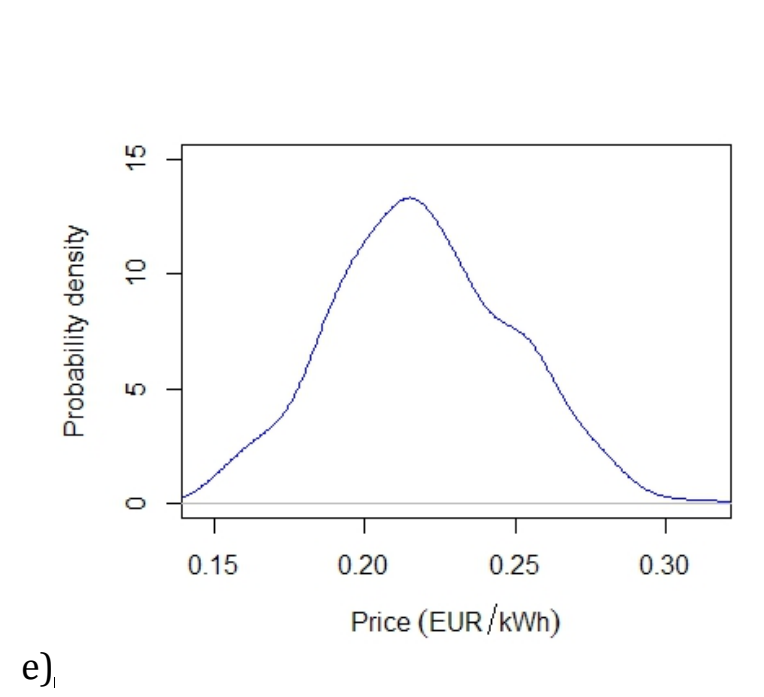

Figure 13- Energy prices generation (Monte-Carlo)

For simplicity, the generation of price scenarios is based on a normal distribution. The standard deviation of prices generated $(\sigma)$ is assumed to be $0.03 € / \mathrm{kWh}$ for all price ranges, while the average $(\mu)$ for each price generation is equal to its current nominal price, as shown in Table 4. Indeed, a correlation between these prices is assumed, so that for the first price (a: local grid to external markets) a normal distribution is generated (Figure 13a), and then the remainder distributions are generated assuming a significant correlation with this first one.

The variations in these price predictions are justified by the volatile changes in the energy prices, so their computation should be based on the perception of the market volatility by the leader decision maker. The values assumed in this work are based on the perception of the energy price volatility in the Spanish market by the authors; obviously this perception significantly affects the specific results obtained in the presented case study, although this does not compromise the usefulness of the presented methodology: from the different generated scenarios, the corresponding reactions from the follower can be anticipated.

\subsection{Coordination Contract}

In the nCNS negotiation scenario, the leader would design the final coordination contract considering the uncertain reaction of the follower in order to estimate its SC expected benefits. Then the results will be analyzed from both leader and follower sides.

\subsubsection{The leader offer}

The leader estimates its expected SC benefits at each negotiation price, based on the follower probability of acceptance values. To calculate the probability of acceptance at each negotiation price, the follower nCNS model is solved for the 500 generated scenarios, and the number of favorable scenarios is obtained (the expected benefits that exceed the Standalone SS expected benefits). Then the probability of acceptance (Eq. 19) is calculated for each negotiation price (Table 6). It is noticed that the probability of acceptance is zero if the offered contract prices are in the range $(0.14-0.16 € / \mathrm{kWh})$, while it increases from offers above $(0.17$ 
$€ / \mathrm{kWh}$ ), till reaching the highest value (100\%) at contract price $0.22 € / \mathrm{kWh}$ (see also Figure 11).

Table 6- Probability of acceptance

\begin{tabular}{|c|c|c|c|c|c|c|c|c|c|}
\hline & 0.14 & 0.15 & 0.16 & 0.17 & 0.18 & 0.19 & 0.2 & 0.21 & 0.22 \\
\hline $\begin{array}{l}\text { No of scenarios where the } \\
\text { follower obtains improved } \\
\text { Profit (contract vs. SS) }\end{array}$ & 0 & 0 & 0 & 89 & 314 & 393 & 440 & 477 & 498 \\
\hline Probability of Acceptance & 0 & 0 & 0 & 0.18 & 0.63 & 0.79 & 0.88 & 0.95 & 1.00 \\
\hline
\end{tabular}

Based on these probabilities of acceptance, the leader assesses its SC expected benefits (Eq. 20) considering its SC benefits in case that the follower accepts or rejects each contract offer (Table 7 and Figure 14). Figure 14 shows the leader production-distribution SC expected benefits vs. the probability of acceptance. It can be noticed that $24.71 \mathrm{GWh}$ of total energy is needed for the leader SC production in order to fulfill the final markets demands. From Table 7 , it is demonstrated that is better for the leader to purchase this amount from the follower at all contract prices, except at $0.22 € / \mathrm{kWh}$, where is better for the leader to purchase a large part from the Local Grid (21.96 GWh) at lower price, between 0.20 and $0.22 € / \mathrm{kWh}$ (see Table 4).

Table 7- Coordination contracts and Leader expected benefits

\begin{tabular}{ccccccc}
\hline $\begin{array}{c}\text { Contract } \\
\text { price } \\
(€ / \mathrm{kWh})\end{array}$ & $\begin{array}{c}\text { Internal } \\
\text { energy } \\
(\mathrm{GWh})\end{array}$ & $\begin{array}{c}\text { Energy } \\
\text { from Grid } \\
\text { (GWh) }\end{array}$ & $\begin{array}{c}\text { Profit if the } \\
\text { follower } \\
\text { accepts (M€) }\end{array}$ & $\begin{array}{c}\text { Profit if the } \\
\text { follower } \\
\text { rejects (M€) }\end{array}$ & $\begin{array}{c}\text { Probability } \\
\text { of } \\
\text { acceptance }\end{array}$ & $\begin{array}{c}\text { Expected } \\
\text { profit } \\
\text { (M€) }\end{array}$ \\
\hline 0.14 & 24.71 & 0 & 9.25 & 7.47 & 0 & 7.47 \\
0.15 & 24.71 & 0 & 8.99 & 7.47 & 0 & 7.47 \\
0.16 & 24.71 & 0 & 8.74 & 7.47 & 0 & 7.47 \\
$\mathbf{0 . 1 7}$ & $\mathbf{2 4 . 7 1}$ & $\mathbf{0}$ & $\mathbf{8 . 4 8}$ & $\mathbf{7 . 4 7}$ & $\mathbf{0 . 1 8}$ & $\mathbf{7 . 6 5}$ \\
$\mathbf{0 . 1 8}$ & $\mathbf{2 4 . 7 1}$ & $\mathbf{0}$ & $\mathbf{8 . 2 3}$ & $\mathbf{7 . 4 7}$ & $\mathbf{0 . 6 3}$ & $\mathbf{7 . 9 5}$ \\
$\mathbf{0 . 1 9}$ & $\mathbf{2 4 . 7 1}$ & $\mathbf{0}$ & $\mathbf{7 . 9 9}$ & $\mathbf{7 . 4 7}$ & $\mathbf{0 . 7 9}$ & $\mathbf{7 . 8 8}$ \\
0.20 & 24.71 & 0 & 7.77 & 7.47 & 0.88 & 7.74 \\
0.21 & 24.71 & 0 & 7.51 & 7.47 & 0.95 & 7.50 \\
0.22 & 2.75 & 21.96 & 7.47 & 7.47 & 1.00 & 7.47 \\
\hline
\end{tabular}




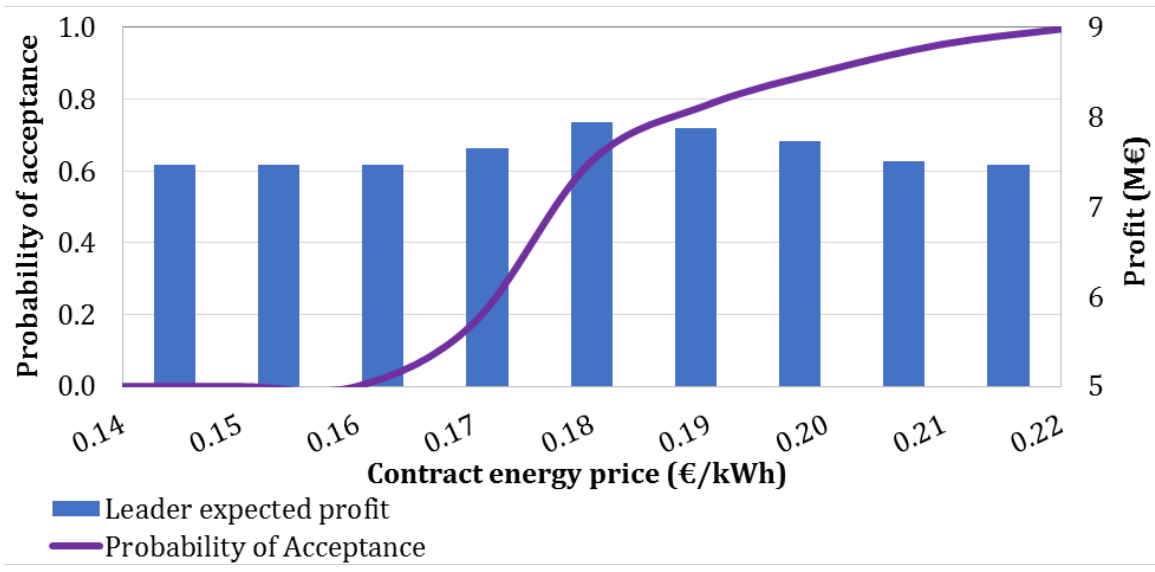

Figure 14- Leader expected Profits vs. Probability of acceptance

It is worth to emphasize the importance of the Grid energy price-quantity constraints. For example, the Local Grid is offering the leader $0.20 € / \mathrm{kWh}$ just when the energy demand exceeds 4GWh each planning time period, but it might be worth for the Leader to maintain its contract with the follower, as it is more evident from Table 8, where the schedule of energy purchase levels from the follower (in case it accepts) along the planning time horizon is explicit. Then, purchasing $24.71 \mathrm{GWh}$ from the follower at the price of $0.21 € / \mathrm{kWh}$ costs the leader $5.19 \mathrm{M} €$, but if the leader purchases these amounts from the Local Grid, this will imply a cost of $5.38 \mathrm{M} €$.

Table 8- Internal energy purchase levels at price $0.21 € / \mathrm{kWh}$

\begin{tabular}{ccccccc}
\hline & $t 1$ & $t 2$ & $t 3$ & $t 4$ & $t 5$ & $t 6$ \\
\hline$P 1$ & 1.47 & 1.47 & 1.59 & 1.47 & 0.75 & 1.47 \\
$P 2$ & 2.56 & 1.53 & 2.56 & 1.53 & 0.95 & 1.31 \\
$P 3$ & 1.53 & 0.67 & 1.53 & 0.67 & 0.67 & 0.98 \\
\hline
\end{tabular}

It is worth noticing that the coordination contract offered by the leader results from the anticipation of the follower's response, which in turn depends on the quality of the knowledge he/she has about the other participants, $3^{\text {rd }}$ parties included, and the way how she/he predicts the market prices. Within the context of the presented case-study, the leader's expected profit (where the follower's uncertain reaction is projected) is considered as the key reference for selecting the coordination contract. The leader's decision-making may have different criteria that can lead to different decisions. Here, we will analyze three options according to the SBDN criteria, which depend on the risk-behaviour of the decision-maker.

From Table 7 it results that, if the leader offers the lowest prices $0.14-0.16 € / \mathrm{kWh}$, she/he would face a $0 \%$ probability of acceptance resulting from the high frequency of negative profit scenarios. This means that the leader should not choose these prices although the potential benefits are higher.

However, an option with a very high probability of acceptance by the follower is not always the smartest decision for the leader, since the coordination might be even unprofitable as the price to be paid to the follower is very high, even higher than the one offered by the local electricity grid (so leader SC should return to its standalone case). For example, for the 
presented case study, when the leader offers the contract with $95 \%$ probability of acceptance, this coordination leads to very low profits $(0.5 \%$ higher than standalone case). So, if the leader's decision-maker is highly risk-averse, she/he may choose this offer. But there are still options with higher profits expectations for the leader $(0.17-0.19 € / \mathrm{kWh})$, being $7.95 \mathrm{M} €$, the highest expected profit for the leader, corresponding to a coordination contract at $0.18 € / \mathrm{kWh}$.

In the following paragraphs, we will analyze the final three coordination contracts according to the risk behavior:

\section{i) Risk-seeking:}

If the leader has a risky behavior, its strategy will be to offer the purchase of 24.71 GWh at $0.17 € / \mathrm{kWh}$ (Table 7), as its SC profit, if the follower accepts, is relatively high (8.48 M€; $14 \%$ more than its SS profit of $7.47 \mathrm{M} €$ ). But in this case, only in $18 \%$ of the expected scenarios the follower will obtain more benefits than its expected standalone benefits.

\section{ii) Risk-neutral:}

If the leader has a risk neutral behavior, its strategy will be to offer the coordination contract of $24.71 \mathrm{GWh}$ at $0.18 € / \mathrm{kWh}$; this leads to $8.23 \mathrm{M} €$ leader profit (10\% more than its SS profit) with the highest expected profit (7.95 M€). Actually, this compensates the leader risk, associated with the fact that in $63 \%$ of the follower scenarios, the follower will gain more than in its expected standalone scenario.

\section{iii) Risk-averse:}

In case the leader has a risk averse behavior, the coordination offer may be to purchase $24.71 \mathrm{GWh}$ at $0.19 € / \mathrm{kWh}$, leading to $7.99 \mathrm{M} €$ benefits if the follower accepts (Table 7) which is $7 \%$ higher than its SS profit, with $7.88 \mathrm{M} €$ of expected benefits. In this case, the probability of acceptance is estimated as $79 \%$.

\subsubsection{The follower response}

The follower response to these different coordination contract possibilities are analyzed separately taking into consideration its SC expected benefits and probabilities. Here, the expected follower benefits are obtained for the 500 generated scenarios, using the MonteCarlo simulation method. The follower response depends also on how risky its organization is (Table 9).

Table 9- Follower expected benefits vs. Leader possible contract offers

\begin{tabular}{ccccc}
\hline $\begin{array}{c}\text { Contract } \\
\text { price } \\
(€ / \mathrm{kWh})\end{array}$ & $\begin{array}{c}\text { Internal } \\
\text { energy } \\
(\mathrm{GWh})\end{array}$ & $\begin{array}{c}\text { Improved profits } \\
\text { probability (\%) }\end{array}$ & $\begin{array}{c}\text { Expected profit if } \\
\text { accepts (M€) }\end{array}$ & $\begin{array}{c}\text { Standalone } \\
\text { expected profit } \\
(\mathrm{M} €)\end{array}$ \\
\hline 0.17 & 24.71 & $18 \%$ & 2.46 & 2.73 \\
0.18 & 24.71 & $63 \%$ & 2.71 & 2.73 \\
0.19 & 24.71 & $79 \%$ & 2.95 & 2.73 \\
\hline
\end{tabular}


Figure 15 illustrates the cumulative probability curves of the follower's expected profits in case of accepting each of the different coordination contracts offered by the leader (0.17-0.19€/kWh), in comparison with the standalone scenario (dotted curves). For example, at price $0.17 € / \mathrm{kWh}$ (Figure $15 \mathrm{a}$ ), the probability to gain more than $4 \mathrm{M} €$ is higher when accepting this contract offer. However, there are many scenarios where the follower is expected to lose with respect the standalone case at expected profits lower than $4 \mathrm{M} €$. When the contract price increases, for example at $0.18 € / \mathrm{kWh}$, the favourable profits scenarios increases, and the probability to gain more than the standalone case is higher. At price $0.19 € / \mathrm{kWh}$, the probability to gain more than the standalone case is higher in most of the generated scenarios.

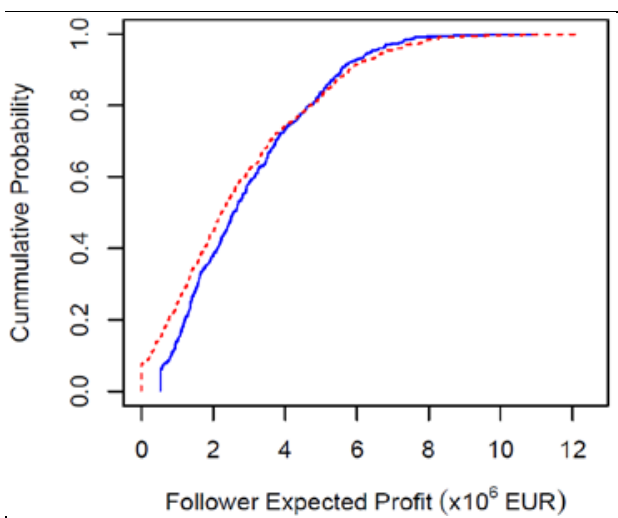

a) $0.17 € / k W h$

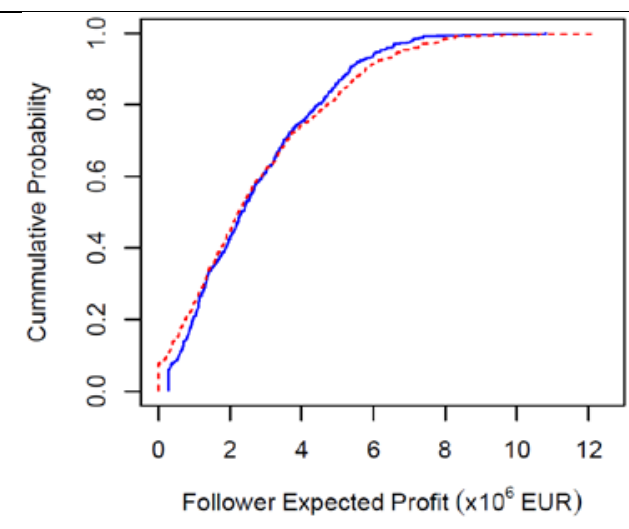

b) $0.18 € / k W h$

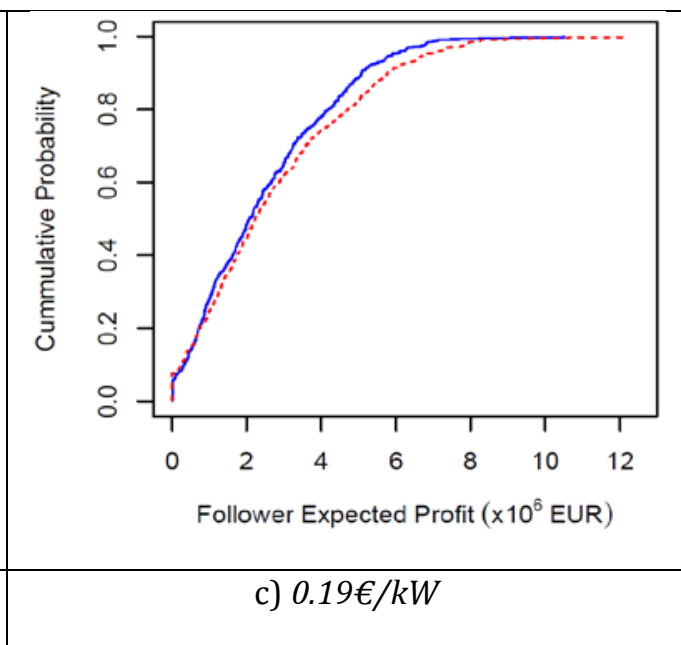

Figure 15- Cumulative probabilities in comparison with the standalone case

\section{i) Risk-seeking response:}

If the follower is a risk-seeker, he is likely to accept the leader risk-seeking strategy (24.71 GWh at $0.17 € / \mathrm{kWh}$ ), taking into consideration that $18 \%$ of the scenarios are profitable with higher probabilities (Figure 15a) compared with the standalone scenario. In this case, $18 \%$ of the uncertain scenarios lead to $22 \%$ improvements in the follower expected benefits compared with the standalone scenario (expected nCNS " $18 \%$ of the scenarios" $=272$ $\mathrm{k} €$; expected SS “18\% of the scenarios" = $222.3 \mathrm{k} €$ ).

\section{ii) Risk-neutral response:}

If the follower is a risk-neutral, he will probably accept the leader risk-neutral offer (24.71 GWh at $0.18 € / \mathrm{kWh})$, as indeed, this compensates the follower, considering that the 63 $\%$ probability that the follower will gain from accepting this offer, with higher frequencies (Figure 15b) compared with its standalone scenario. In this case, $63 \%$ of the uncertain scenarios (Table 6) lead to $12 \%$ expected benefits improvements, compared with standalone scenario (expected nCNS = 1.5 M€; expected SS = 1.34 M€). 
iii) Risk-averse response:

If the follower is a risk-averse, he will probably accept the leader risk-averse offer (24.71 GWh at $0.19 € / \mathrm{kWh}$ ), based on the $79 \%$ probability of profits improvements with higher probabilities (Figure 15c). In this case, 393 risk scenarios (79\% of the 500 uncertain scenarios. See Table 6) lead to $19 \%$ expected profits improvements compared with the same 393 standalone benefits (expected nCNS = 2.17 M€; expected SS = 1.82 M€).

Most of the works in the literature assume a risk behavior and analyze one coordination contract. This work proposes a flexible approach that may be adopted by any risk behavior decision-maker. With this methodology, the decision-makers of the leader and the follower may have a decision-support tool to evaluate the effects of their decisions (e.g. the three coordination/collaboration contracts based on the risk behavior of the decisionmakers)

\subsection{Leader tactical decisions}

The leader tactical and economic decisions are analyzed for the three possible risk strategies considered, and compared with the corresponding ones at the Standalone Scenario. The goal here is to study the effect of considering the uncertain reaction of the follower (resulting in the three possible coordination agreements) on the leader tactical decisionmaking.

\subsubsection{Leader risk-seeking strategy:}

Table 10 summarizes the tactical decisions of the leader production-distribution SC resulted from the nCNS coordination contract ( $24.71 \mathrm{GWh}$ at $0.17 € / \mathrm{kWh}$ ), compared with its standalone case. The total RM purchase amount is the same in both cases $(3,450$ tons) and the total production is the same (3,380 tons) as well. The decision in both cases is to fulfill the total polystyrene market demands. Using the risk-seeking coordination contract, results in $13 \%$ improvements in the total inventory in comparison with the SS case. On the other hand, it leads to $4 \%$ increase in the total distribution levels. To understand the reason behind these results, the tactical decision levels along the planning time horizon are analyzed in the next paragraph.

Table 10- Leader tactical decisions-breakdown (risk-seeking strategy)

\begin{tabular}{lll}
\hline & nCNS & SS \\
\hline RM purchase (tons) & $3,449.75$ & $3,449.75$ \\
Energy from Grid (GWh) & 0 & 24.71 \\
Internal Energy (GWh) & 24.71 & 0 \\
Production (tons) & $3,380.40$ & $3,380.40$ \\
Distribution (k.tons.km) & $1,328.19$ & $1,271.50$ \\
Inventory (tons.h) & 468.90 & 530.18 \\
\hline
\end{tabular}

Figure 16a shows the energy demanded for the polystyrene production using the riskseeking strategy (coordination contract: $24.71 \mathrm{GWh}$ at $0.17 € / \mathrm{kWh}$ ) along the planning time 
horizon, comparing with the energy levels demanded from the Local Grid using the standalone SS (Figure 16b). It is noticed that using the nCNS gives the leader more freedom to purchase different energy amounts (considering the same price $0.17 € / \mathrm{kWh}$ ) and to distribute them among all polystyrene manufacturing plants, with the highest energy portion to the manufacturing plant pl2 (38\% of the total energy demand). On the other hand, using the SS, the leader has to purchase energy from the Local Grid with higher amounts in order to get lower price $(0.22-0.20 € / \mathrm{kWh})$. The decision in this case is to purchase most of the energy amounts $(>2 \mathrm{GWh})$ for the manufacturing plants $p l 2$ and $p l 1$ to gain the energy price 0.21 $€ / \mathrm{kWh}$ (as pl2 dominates producing product A, Figure 17b), while the rest is to be purchased for the manufacturing plant $p l 3$ at $0.22 € / \mathrm{kWh}$. It is noticed also that the energy demand is the highest at time period $t 4$, where the polystyrene production reaches its highest levels to satisfy the high markets demands at this time period (Figure 17a and b).
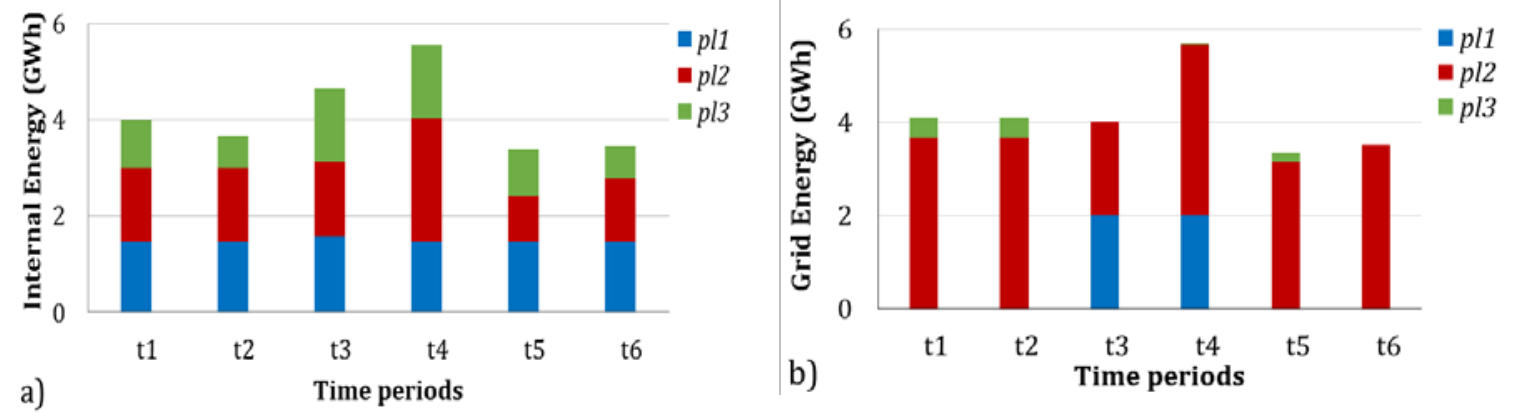

Figure 16- Leader SC energy demands (risk-seeking)
a) nCNS
b) SS

Figure 17 shows the leader polystyrene production levels along the planning horizon. It is noticed that using the coordination contract (nCNS: $24.71 \mathrm{GWh}$ at $0.17 € / \mathrm{kWh}$ ) affects the polystyrene production levels (Figure 17a), although the total amount is the same, thus leading to activate all the manufacturing plants all time periods. This is due to the different energy purchase levels, and explains why the distribution levels using the nCNS are higher than the SS, as there are wider distribution connections to all manufacturing plants all time periods. It is also noticed that the polystyrene production levels of products A and B at time period $t 2$ using the SS exceed the market demand, in which the excess will be stored for later distribution, and this explains why the inventory levels using the SS is higher than using the nCNS (Table 10).

To produce product A: it is noticed that the polystyrene manufacturing plant $p l 2$ dominates the production levels of product $A$ in both nCNS (1,134 tons; $67 \%$ of the total product A), and SS (1,419 tons; $84 \%$ of the total product A), although the total product $A$ is the same for both scenarios (1,690 tons). Such a difference is due to the higher energy amounts assigned to the manufacturing plant pl2 in the SS case (see Figure 16b). It is worth mentioning that the high production levels of pl2 in both nCNS and SS can be explained by its short distance to the $r m 2$ supplier (sup2) (see Table1), which is dominating the RM purchase levels ( $49 \%$ of the total RM) for producing product A (see Figure 18). 

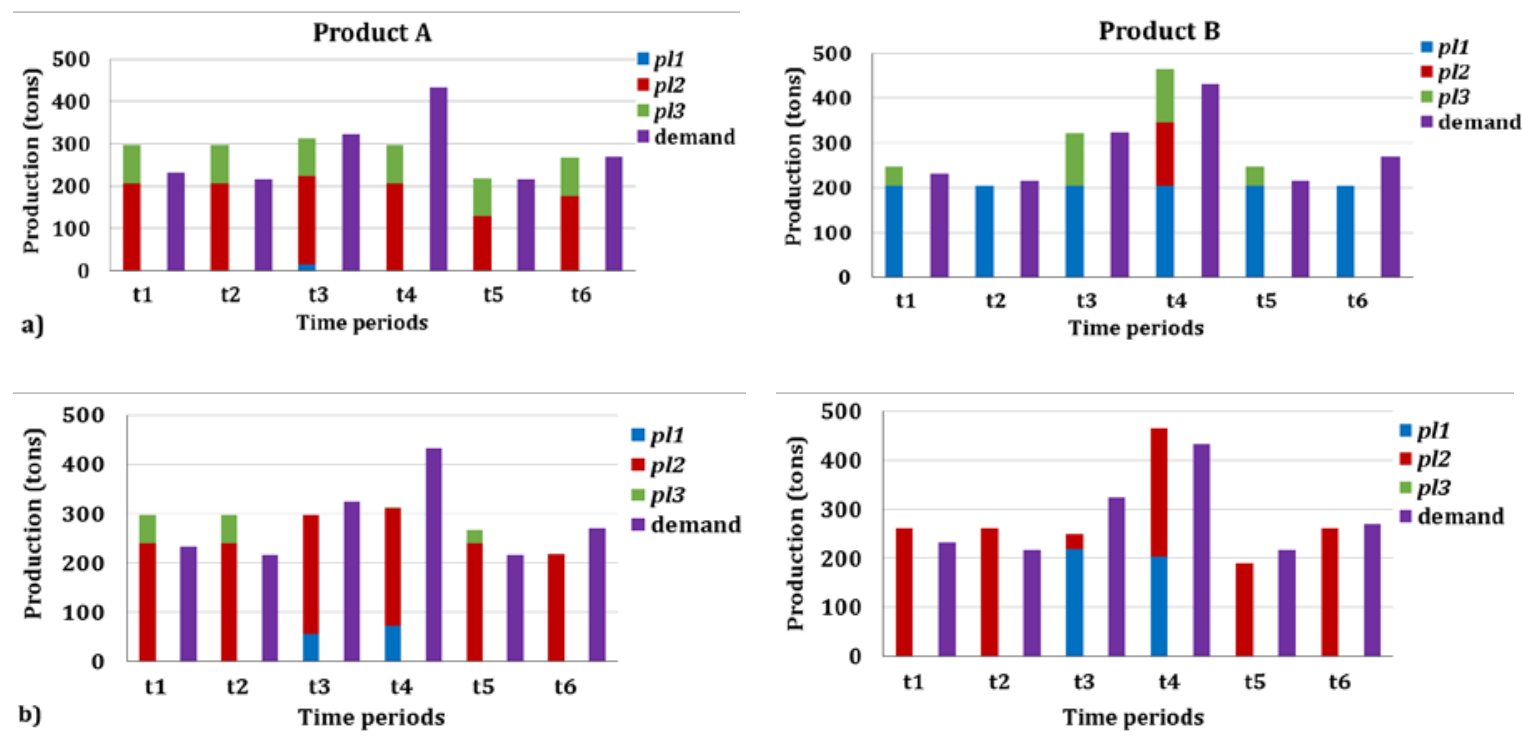

Figure 17- Leader SC production levels (risk-seeking strategy)
a) $\mathrm{nCNS}$
b) SS

To produce product B: the manufacturing plant $p l 1$ dominates the production levels using the nCNS (72\% of total product B), as it is the closest to the RM rm4 supplier (sup4) (see Table 1), which dominates the RM supplying (37\% of the total RM, see Figure 18a). It is worth mentioning here that the $r m 4$ has lower price than $r m 3$ (Figure 19) and lower capacity; the decision is thus to purchase the highest $r m 4$ amounts (210 tons) each planning time period to get the highest discount from the third party, adding to its lower production cost in comparison with rm3 (Table 2). That explains why the total RM and production costs are lower using the nCNS. For the SS scenario, the manufacturing plant $p / 2$ dominates the product B production levels (75\% of total product B), as it is the closest to the RM rm3 supplier (sup3) which dominates the RM supplying (38\% of the total RM purchase (Figure 18b). This happens because the decision is to buy high amounts of $r m 3$ due to its higher capacity (although lower cost than rm4, see Figure 19).
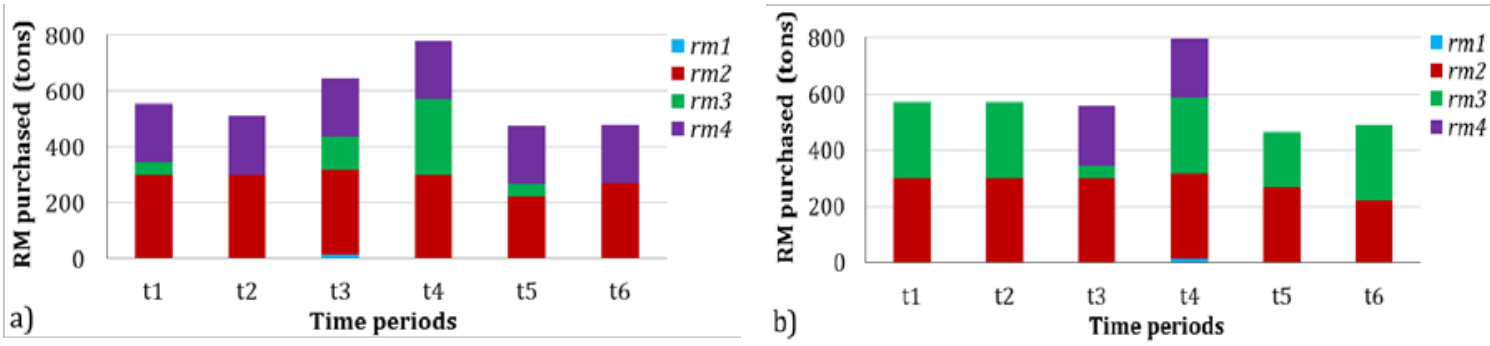

Figure 18- Leader SC RM purchase levels (risk-seeking strategy)

$\begin{array}{ll}\text { a) } \mathrm{nCNS} & \text { b) SS }\end{array}$ 


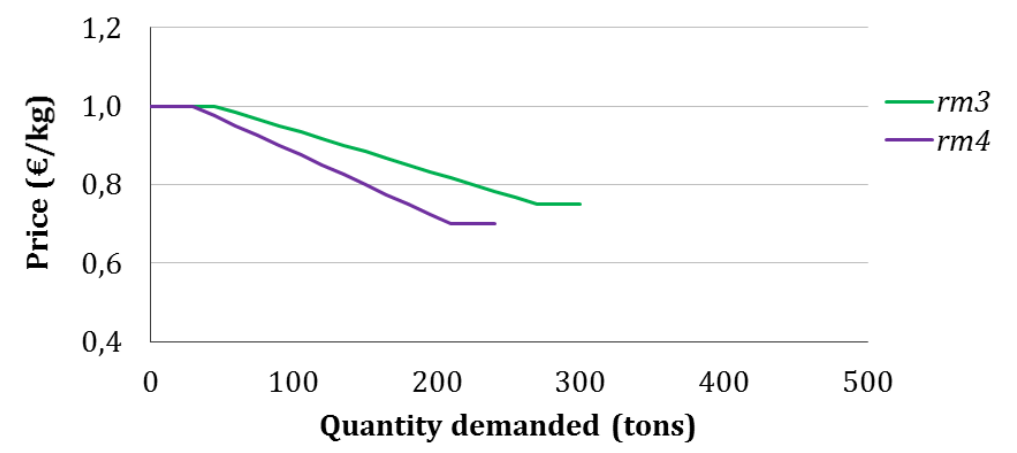

Figure 19- Leader SC RM purchase levels vs. prices (Reference: Hjaila et al., 2016)

Figure 20 illustrates the economic breakdown of the leader production-distribution SC resulted from the risk-seeking strategy. Using the nCNS leads to 24\% improvements in the energy purchase cost ( 1 M€ savings); $1 \%$ in the RM purchase cost (26.79 k€ savings); and 2 $\%$ in the total polystyrene production cost (40.71 k€), in comparison with its Standalone SS case.

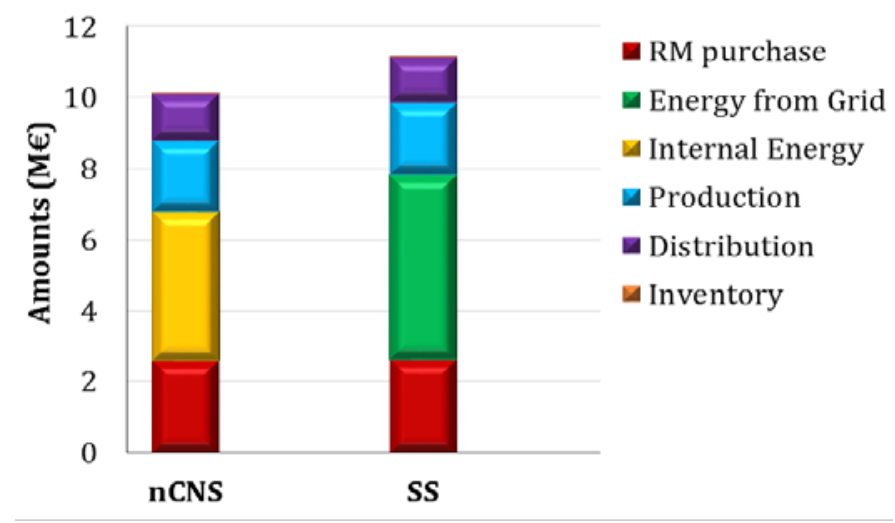

Figure 20- Leader economic decisions (risk-seeking strategy)

Table 11 summarizes the final economic decisions of the leader in case of using the risk-seeking strategy in comparison with its SC standalone case (SS). Considering that the decision in both cases is to fulfill the final market demands (resulting in $18.59 \mathrm{M} €$ total sales), using the risk-strategy leads to $14 \%$ improvements in the leader SC benefits.

Table 11- Leader SC economic summary (risk-seeking)

\begin{tabular}{lcc}
\hline & nCNS & SS \\
\hline Cost (M€) & 10.11 & 11.12 \\
Sales (M€) & 18.59 & 18.59 \\
Profit $(M €)$ & 8.48 & 7.47 \\
\hline
\end{tabular}

\subsubsection{Leader risk-neutral strategy}

In case the leader is a risk-neutral, Table 12 summarizes its production-distribution SC tactical decisions resulting from the coordination contract $(24.71 \mathrm{GWh}$ at $0.18 € / \mathrm{kWh})$, in comparison with its SC standalone SS. The total RM purchase quantity is the same in both 
cases $(3,450$ tons $)$ and the total production is also the same $(3,380$ tons), as the leader decision is to fulfill the total polystyrene market demands. It is noticed that using the riskneutral nCNS coordination contract results in 7\% improvements in the total inventory, in comparison with the SS case, while leading to $5 \%$ increase in the total distribution levels, for the same reasons explained before.

Table 12- Leader tactical decisions-breakdown (risk-neutral)

\begin{tabular}{lll}
\hline & nCNS & SS \\
\hline RM purchase (tons) & $3,449.75$ & $3,449.75$ \\
Energy from Grid (GWh) & 0 & 24.71 \\
Internal Energy (GWh) & 24.71 & 0 \\
Production (tons) & $3,380.40$ & $3,380.40$ \\
Distribution (k.tons.km) & $1,332.07$ & $1,271.50$ \\
Inventory (tons.h) & 495.00 & 530.18 \\
\hline
\end{tabular}

Figure 21 illustrates the economic decisions breakdown of the leader in case of using the riskneutral strategy. Using the nCNS risk-neutral strategy leads to $17 \%$ improvements in the total energy purchase cost ( $0.75 \mathrm{M} €$ savings); $1 \%$ improvements in the RM purchase cost (25.72 $\mathrm{k} €$ savings); and $2 \%$ improvements in the total polystyrene production cost (42.24 k€), when compared with its Standalone SS case.

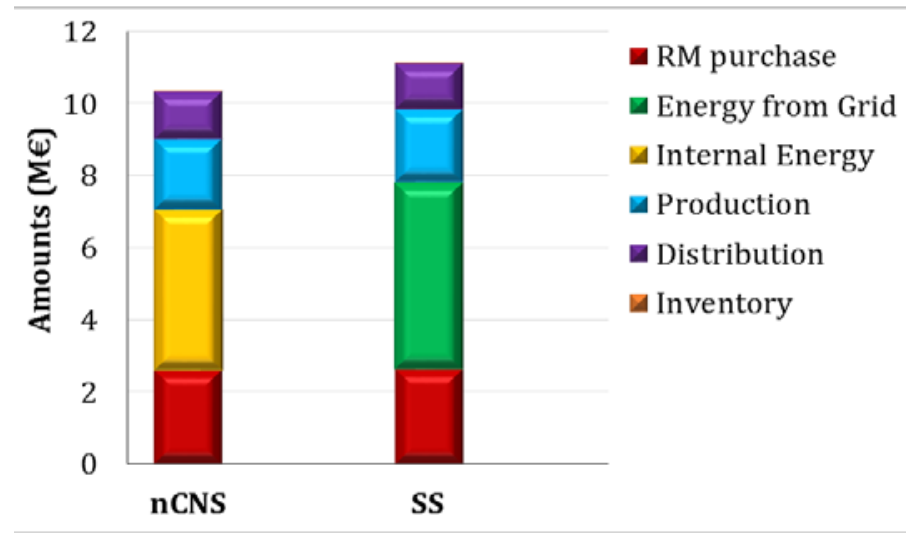

Figure 21- Leader economic decisions (risk-neutral)

Table 13 summarizes the final economic decisions of the leader in case of using the risk-neutral strategy, in comparison with its SC standalone case (SS). Considering that the decision in both cases is to fulfill the final market demands, it results in $18.59 \mathrm{M} €$ total sales, with $10 \%$ improvements in the leader SC benefits.

Table 13- Leader SC economic summary (risk-neutral)

\begin{tabular}{lcc}
\hline & nCNS & SS \\
\hline Cost (M€) & 10.36 & 11.12 \\
Sales (M€) & 18.59 & 18.59 \\
Profit (M€) & 8.23 & 7.47 \\
\hline
\end{tabular}

\subsubsection{Leader risk-averse strategy}


Table 14 summarizes the tactical decisions of the leader in case of deciding to avoid risk (coordination contract: $24.71 \mathrm{GWh}$ at $0.19 € / \mathrm{kWh}$ ), compared with its SC standalone case. It is to be noticed that using the risk-averse nCNS coordination contract results in an improvement of $13 \%$ in the total inventory levels, while leading to $4.3 \%$ increase in the total distribution levels, in comparison with the SS case.

Table 14- Leader tactical decisions-breakdown (risk-averse)

\begin{tabular}{lll}
\hline & nCNS & SS \\
\hline RM purchase (tons) & $3,449.75$ & $3,449.75$ \\
Energy from Grid (GWh) & 0 & 24.71 \\
Internal Energy (GWh) & 24.71 & 0 \\
Production (tons) & $3,380.40$ & $3,380.40$ \\
Distribution (k.tons.km) & $1,328.19$ & $1,271.50$ \\
Inventory (tons.h) & 468.90 & 530.18 \\
\hline
\end{tabular}

Figure 22 illustrates the economic decisions of the leader in case of using the risk-averse strategy, leading to $11 \%$ improvements in the total energy purchase cost ( $0.51 \mathrm{M} €$ savings); 1 $\%$ in the RM purchase cost (26.79 k€ savings); and $2 \%$ in the total production cost (40.71 $\mathrm{k} €)$, when compared with its SC standalone case.

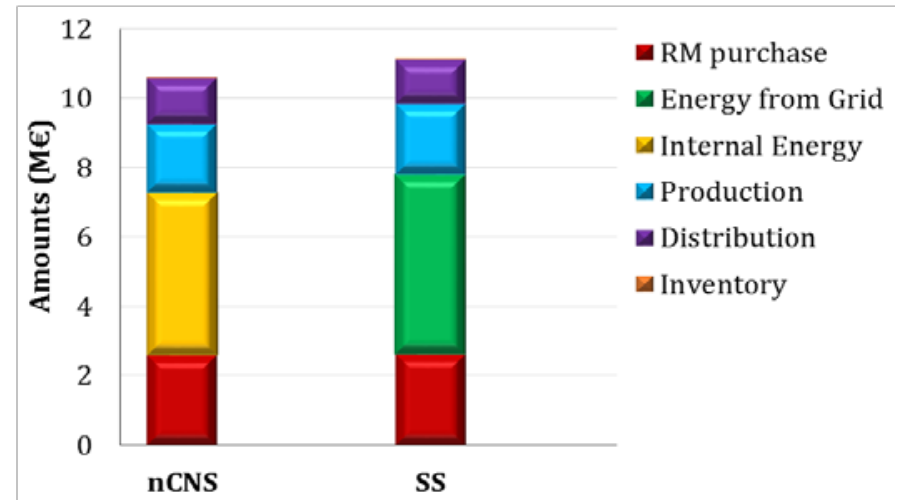

Figure 22- Leader tactical decisions (risk-averse)

Table 15 summarizes the final economic decisions of the leader in case of using the risk-averse strategy, compared with its SC standalone case (SS), resulting in $7 \%$ improvements in the leader SC benefits.

Table 15- Leader SC economic summary (risk-averse)

\begin{tabular}{lcc}
\hline & nCNS & SS \\
\hline Cost (M€) & 10.61 & 11.12 \\
Sales (M€) & 18.59 & 18.59 \\
Profit (M€) & 7.99 & 7.47 \\
\hline
\end{tabular}

\subsection{Follower expected tactical decisions}


The expected tactical decisions of the follower are analyzed next based on the 500 generated scenarios at the nCNS, in comparison with its SC standalone case. Figure 23 shows the expected energy flows around the follower SC at its standalone case.

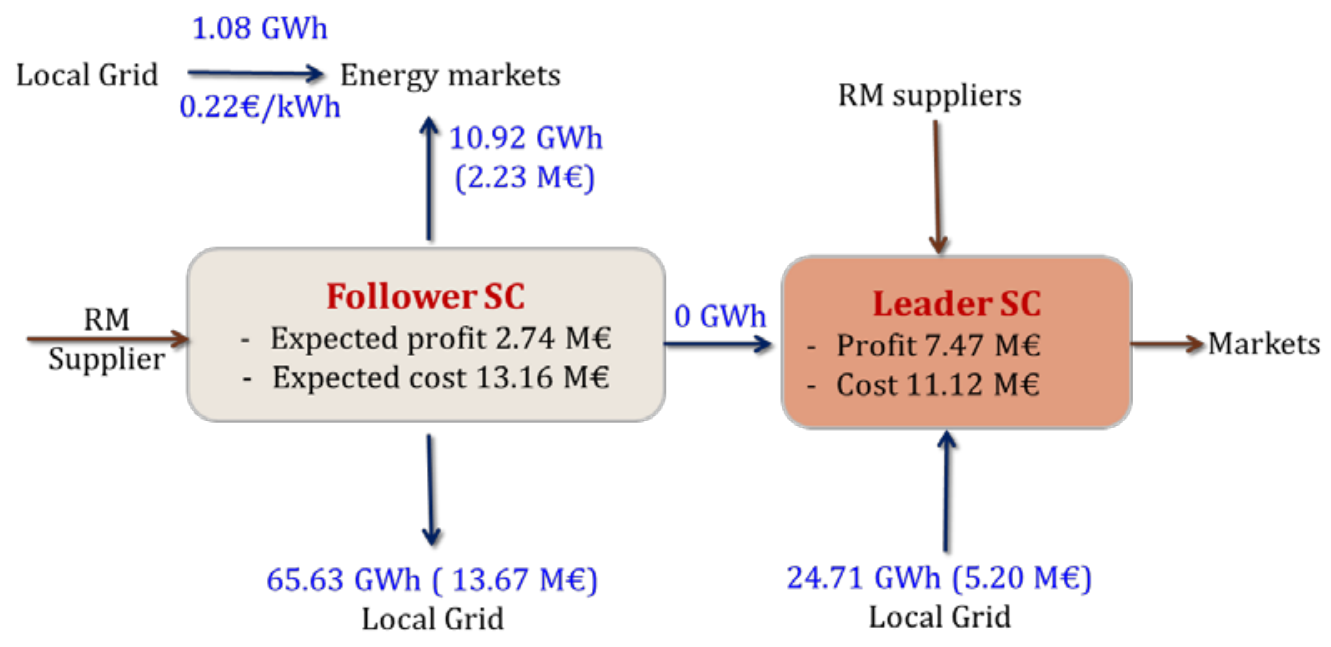

Figure 23- Expected energy flows (SS)

The follower expected tactical decisions then will be analyzed for each risk-response the follower could make, comparing with its above-mentioned standalone case.

\subsubsection{Follower risk-seeking response}

In case the follower accepts the leader risk-seeking strategy (coordination contract: $24.71 \mathrm{GWh}$ at $0.17 € / \mathrm{kWh}$ ), the follower SC is expected that will generate $15 \%$ more energy in order to be able to sell the $24.71 \mathrm{GWh}$ to the leader SC (Figure 24), leading to $18 \%$ reductions in the expected energy sales to Local Grid, and $20 \%$ reductions in the expected total sales to the external energy markets, in comparison with its expected standalone case. Here, one may say that the follower should sell more energy to the Grid in order to compensate, but in fact, its expected SC total cost is also increasing. Generating those $15 \%$ extra energy leads to $14 \%$ increase in its expected SC total cost, in comparison with its expected standalone case (difference of $2.21 \mathrm{M} €$ ), whereas the contract price is still low to compensate the sales of the follower. 


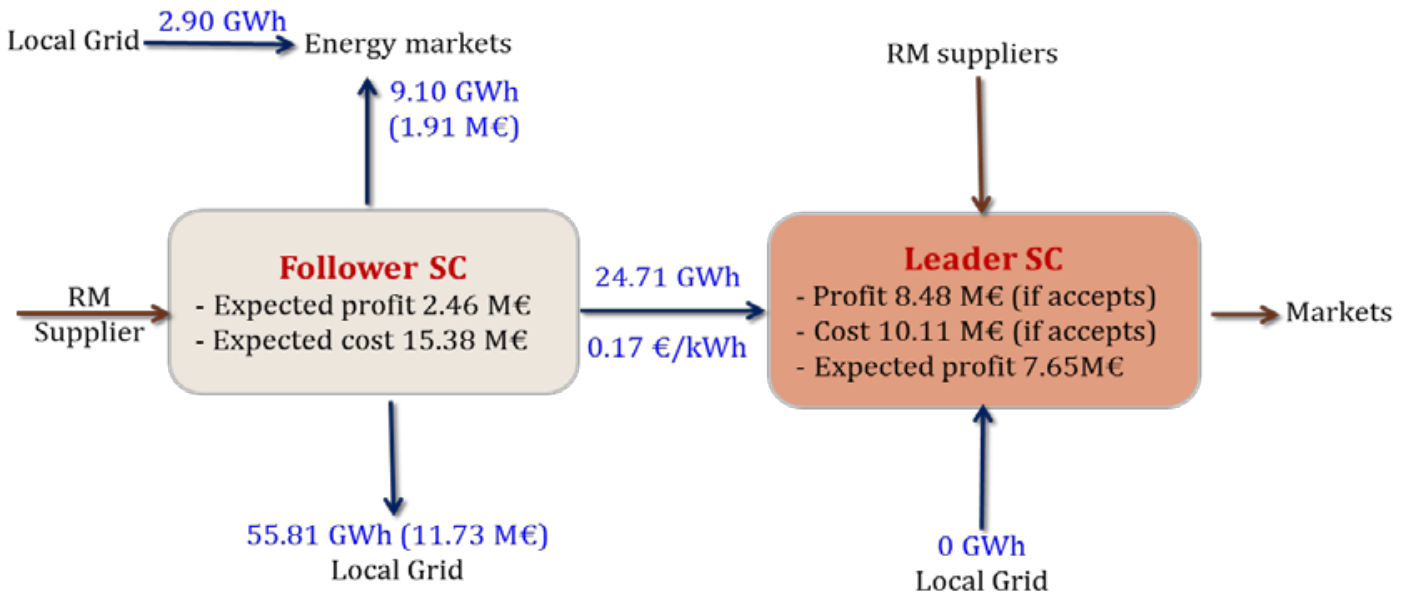

Figure 24- Expected energy flows (risk-seeking)

Figure 25 shows the expected energy generation levels along the planning time horizon resulting from accepting the leader risk-seeking strategy (Figure 25a), compared with rejecting it (Figure 25b). It is noticed that the expected energy generation is distributed equally between the energy generation plants $(g 4, g 5$, and $g 6)$ with 15 GWh energy generation per time period using the risk-seeking strategy (nCNS); $15 \%$ higher than the standalone case (Figure 25b), in order to sell the high amount of energy needed by the leader $(24.71 \mathrm{GWh})$. The rest is to be reduced from the energy sales to the Grid and to the external energy markets. It is worth mentioning that each energy generation plant has a capacity of $6 \mathrm{GWh}$, but in this case, the expected cost of operating up to their full capacity does not compensate the follower. This takes into consideration that generating the energy plants $(g 1$, $g 2$, and $g 3$ ) is expensive for the follower, due to their lower efficiency (see Table 3). This strategy leads to an $18 \%$ higher of the expected RM purchase amounts, in comparison with the expected standalone case.
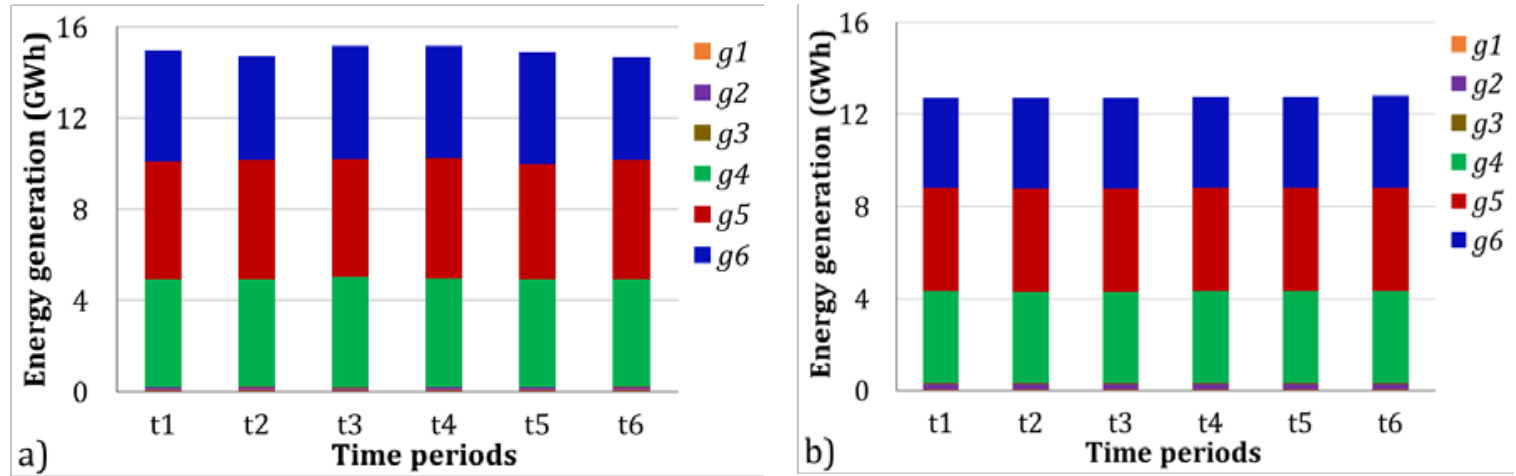

Figure 25- Expected energy generation levels (risk-seeking)

a) $\mathrm{nCNS} \quad$ b) $\mathrm{SS}$

Figure 26 summarizes the follower expected economic decisions according to the leader risk-seeking strategy, in comparison with its expected standalone decisions. It is noticed that the coordination contract $(24.71 \mathrm{GWh}$ at $0.17 € / \mathrm{kWh})$ leads to $14 \%$ increase in 
the expected energy generation cost, resulting in $16 \%$ increase in the expected RM purchase cost, and consequently to $17 \%$ decrease in the expected energy sales to the Grid; and $17 \%$ decrease in the expected energy sales to the external markets, compared with its expected standalone case.

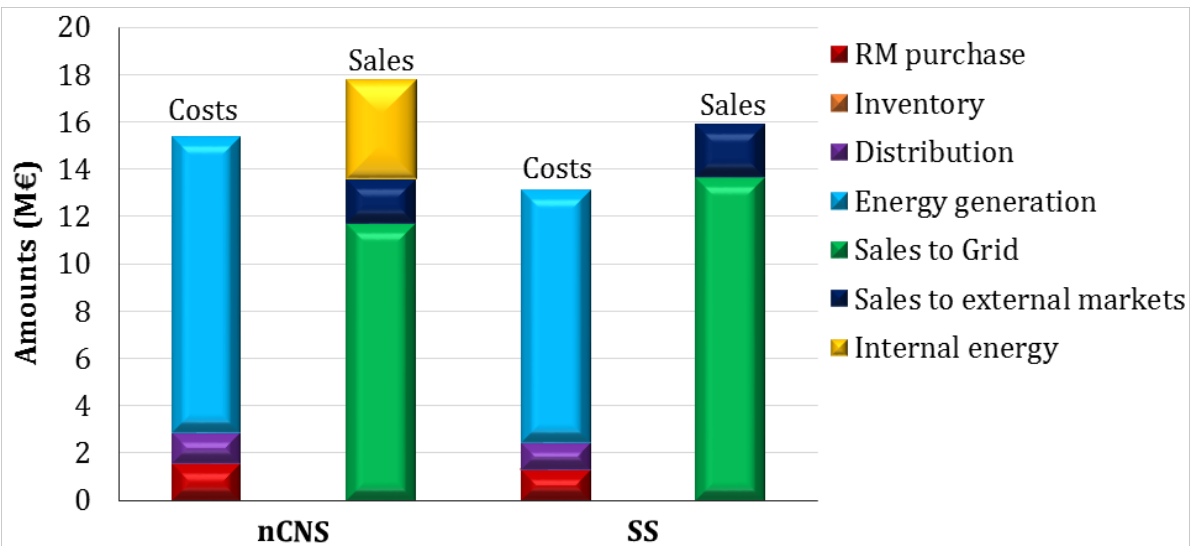

Figure 26- Follower expected tactical decisions (risk-seeking)

Table 16 summarizes the follower final expected economic decisions in case of accepting the leader risk-seeking strategy, in comparison with its expected standalone case (SS). Considering all the expected benefits resulted from the 500 risk scenarios (positive and negative cases), the proposed coordination contract results in $10 \%$ reductions in the follower total expected profit. However, as we mentioned before, the follower would risk and accept based on the $22 \%$ expected profits improvements resulting from the $18 \%$ improved probabilities.

Table 16- Follower expected economic summary (risk-seeking)

\begin{tabular}{lcc}
\hline & NCNS & SS \\
\hline Cost (M€) & 15.38 & 13.16 \\
Sales (M€) & 17.83 & 15.90 \\
Profit (M€) & 2.46 & 2.74 \\
\hline
\end{tabular}

\subsubsection{Follower risk-neutral response}

It is expected that the follower SC will generate $15 \%$ more energy than the SS (Figure 29 ) in order to sell the $24.71 \mathrm{GWh}$ to the leader. $63 \%$ of the total energy generation is expected to be sold to the Local Grid, while the rest is expected to be sold to the leader SC (27 $\%)$ and to the external energy markets (10\%). This leads to $15 \%$ increase in the expected SC cost (Figure 27 and Figure 28), in comparison with standalone case. 


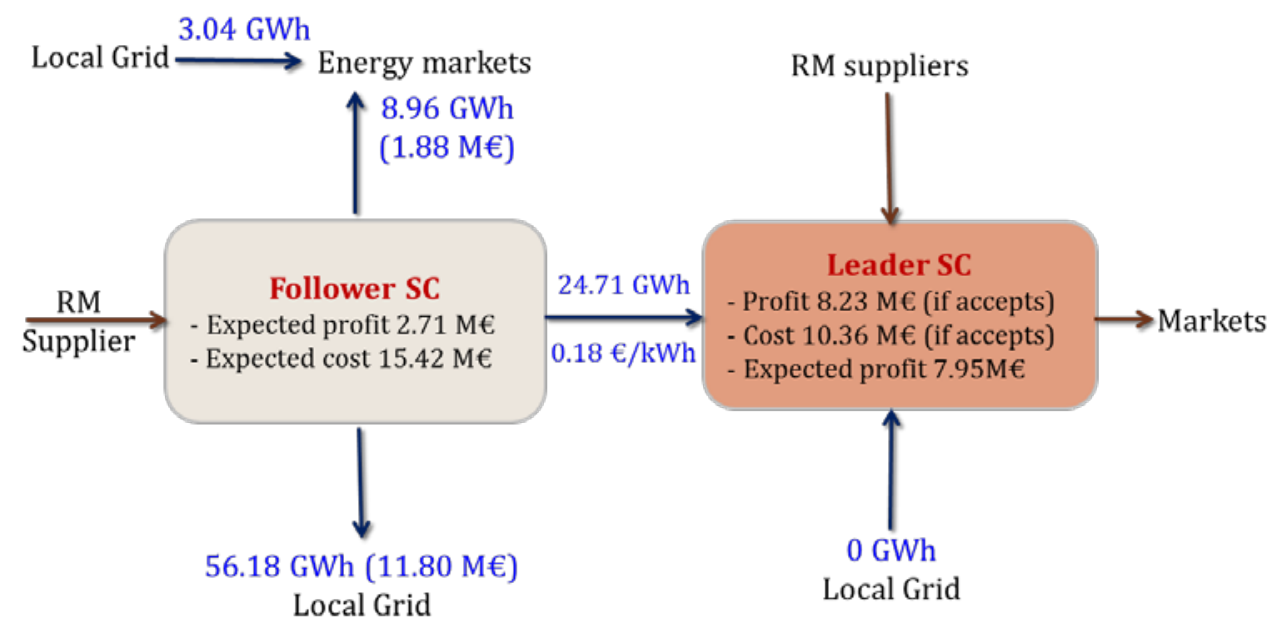

Figure 27- Expected energy flows (risk-neutral)

Figure 28 summarizes the follower's expected economic decisions according to the leader's risk-neutral strategy, compared with the standalone case. The coordination contract, results in a $14 \%$ increase in the expected energy generation cost, ensuing in a $16 \%$ increase in the expected RM purchase cost, and $16 \%$ decrease in the expected energy sales to the Grid, as well an $18 \%$ decrease in the expected energy sales to the external markets, compared with its expected standalone decisions.

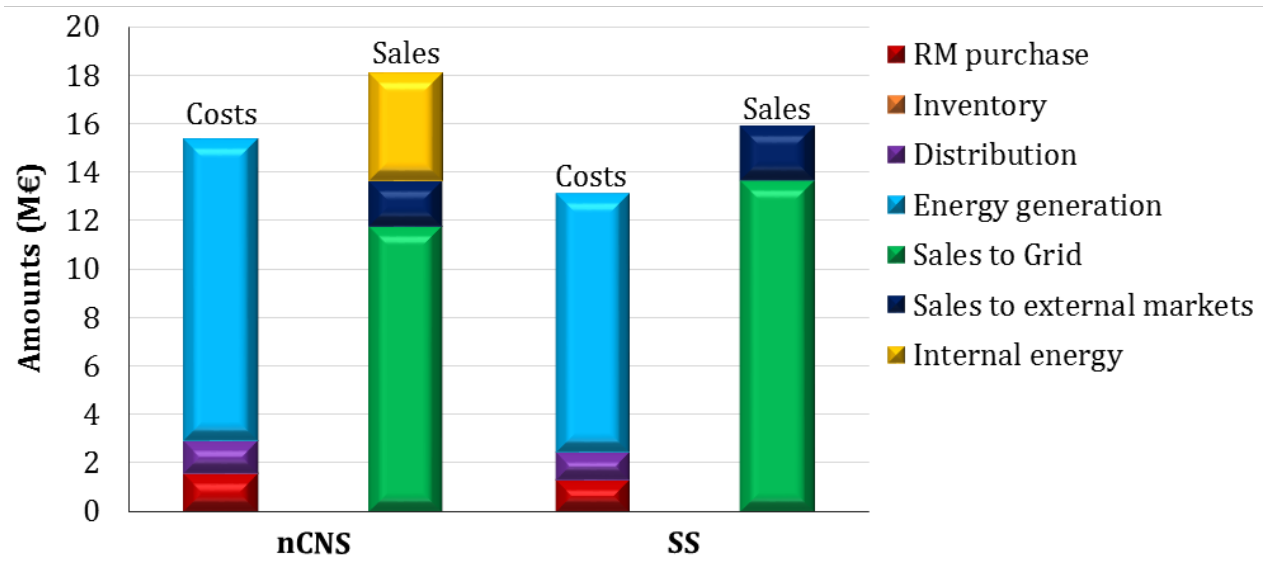

Figure 28- Follower expected economic decisions (risk-neutral)

Table 17 summarizes the final expected economic decisions of the follower in case of accepting the leader risk-neutral strategy, in comparison with its expected standalone case. Considering all risk scenarios (the improved $63 \%$ and the $37 \%$ negative cases), the proposed coordination contract gives similar total expected profits as the expected standalone case. Nevertheless, as we mentioned before, the follower would accept, based on the $12 \%$ expected profit improvement resulting from the $63 \%$ improved probability.

Table 17- Follower expected economic summary (risk-neutral)

\begin{tabular}{ccc}
\hline & NCNS & SS \\
\hline Cost $(\mathrm{M} €)$ & 15.42 & 13.16
\end{tabular}




\begin{tabular}{lcc} 
Sales $(\mathrm{M} €)$ & 18.13 & 15.90 \\
Profit $(\mathrm{M} €)$ & 2.71 & 2.74 \\
\hline
\end{tabular}

\subsubsection{Follower risk-averse response}

In this case, the follower SC is expected to generate 15\% more energy than the SS (Figure 29), $62 \%$ of the total energy generation is expected to be sold to the Local Grid, while the rest is expected to be sold to the leader SC (28\%) and to the external energy markets (10 $\%)$.

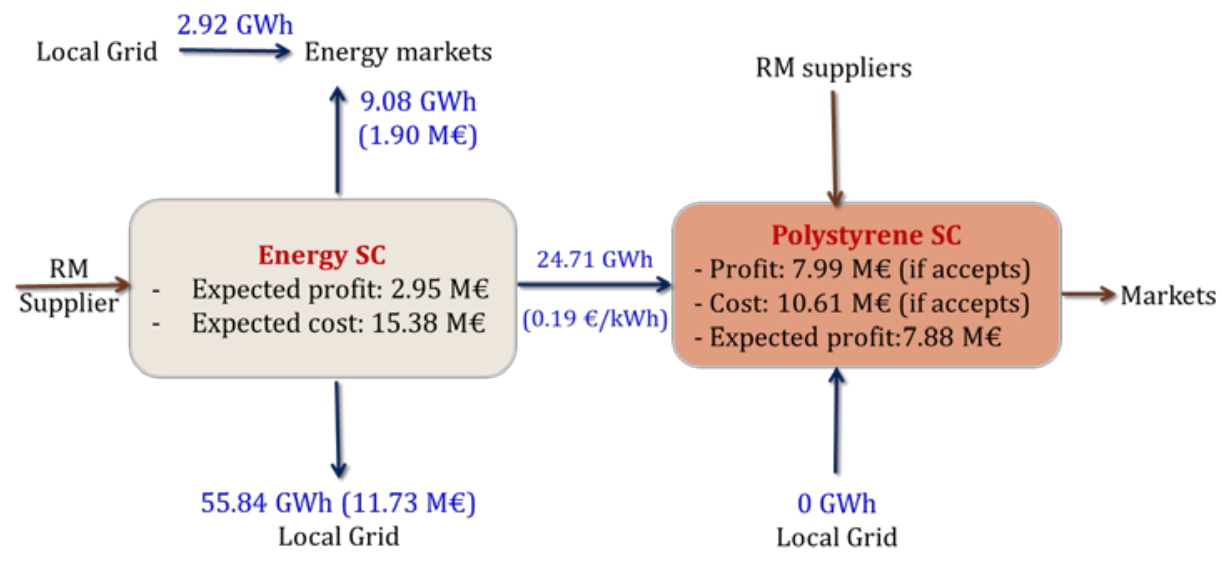

Figure 29- Expected energy flows (risk-averse)

Figure 30 summarizes the follower expected economic decisions according to the leader's risk-averse strategy, compared with the expected standalone decisions. The coordination contract results in $16 \%$ increase in the expected RM purchase cost, and accordingly to $14 \%$ increase in the expected total SC cost (Table 18).

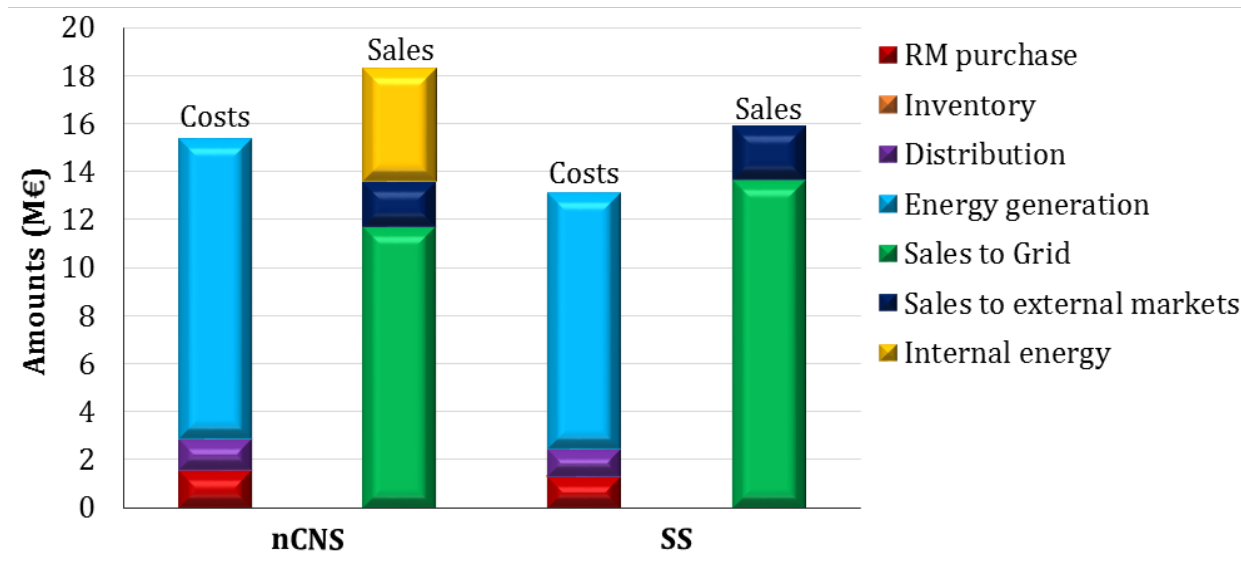

Figure 30- Follower expected economic decisions (risk-averse)

Table 18 summarizes the final expected economic decisions of the follower in case of accepting the leader's risk-averse strategy, in comparison with the expected standalone case. Considering all risk scenarios (the improved $79 \%$ and the $21 \%$ negative cases), the coordination contract proposed results in an $8 \%$ profit improvement $(0.21 \mathrm{M} €)$, compared 
with the expected standalone benefits. Furthermore, the follower would accept based on the $19 \%$ expected profit improvement, resulting from the $79 \%$ improved probability.

Table 18- Follower expected economic summary (risk-averse)

\begin{tabular}{lcc}
\hline & nCNS & SS \\
\hline Cost (M€) & 15.38 & 13.16 \\
Sales (M€) & 18.33 & 15.90 \\
Profit (M€) & 2.95 & 2.74 \\
\hline
\end{tabular}

As a final result, unlike the current negotiation methods, and to be able to capture high competitive situations (external suppliers/markets), the proposed SBDN approach does not give a full dominance to the leader, indeed, the follower has some "embedded" leadership, resulting in reductions in the expected leader benefits. Furthermore, the uncertain nature of the third parties affects the follower's reaction to the leader strategies, and thus plays a important role in the decision-making of decentralized SC and in the negotiation outcome.

\section{Conclusions}

Due to the volatility of the market, enterprises seek to change their way in managing their SCs by collaborating with other partner SCs in order to enhance their benefits. In this framework, and in order to avoid double marginalization of the markets, a contract is a must; and since any contract is between two organizations, the other participants in the decentralized SC systems must be considered as third parties. So in this work, a novel Scenario-Based Dynamic Negotiation (SBDN) approach has been proposed in this work aiming to help the SC managers to make efficient decisions for global decentralized multi-site, multi-product SCs subjected to uncertain competitive conditions in the presence of third partners.

The proposed approach is based on establishing the best conditions for the coordination/collaboration contracts between partners with conflicting objectives through negotiations built on expected win-to-win principles. The interaction between the partners (client and provider, both represented as full SCs, and third parties) is captured through noncooperative dynamic SBDN negotiation with non-zero-sum non-symmetric roles. The client, "as leader", designs a set of offers (coordination/collaboration contracts) taking into account the uncertain reaction of the provider ("follower") resulting from the uncertain nature of the follower SC behavior and its third parties, which is modeled as a probability of acceptance. Here, the probability of acceptance is able to capture the variations between the profits scenarios resulted from a Monte-Carlo simulation method.

As a result, different negotiation scenarios can be analyzed based on individual and global objectives: i) Cooperative Negotiation Scenario (CNS), and ii) Non-Cooperative Negotiation Scenario (nCNS), and iii) Standalone Scenario (SS). Furthermore, a final decision-making methodology is proposed to help both the leader and the follower to evaluate the final coordination contract, based on different risk strategies (risk-seeking, risk-neutral, and riskaverse). 
The proposed approach has been implemented through the formulation and combination of different tactical MINLP flexible models, which have been applied to a case study of a decentralized large-scale SC composed by different providers' SCs around an industrial production/distribution SC ("leader"). The results show how the uncertain nature of the third parties is expected to affect the follower reaction to the leader strategies, and thus affects the tactical decisions of the leader as well as the expected tactical reactions of the follower. Using the proposed SBDN approach, it is possible to manage non-Cooperative Negotiation Scenarios (nCNS) in order to identify and manage high individual profit expectations likely to be accepted by all partners/players.

The third parties participate in the decision-making through their price policies, influencing the management of the SC financial flows and helping to stay competitive. Furthermore, the third parties (external providers/clients) are competing with other negotiating partners which might be part of a different SC functioning as standalone case. This flexibility to accept/reject the coordination, which counts as added value of the proposed approach, is based on the estimation of the price policies of the competing parties, which are integrated into the model formulation. By doing so, equilibrium situations result between the negotiating partners and the $3^{\text {rd }}$ parties. The characteristics of this equilibrium will be further investigated in the future works.

The proposed approach identifies situations where the coordination may lead to higher expected benefits for all partners, proposing a flexible procedure able to cope with the different risk behaviours of the decision makers, which can be applied to real cases when different enterprises seek to collaborate under uncertain conditions. Using the proposed SBDN systematic, the decision-makers will be able to evaluate the effects of their decisions and the other partners' decisions on their choice. The use of Monte-Carlo sampling method adds value to the proposed approach, as both leader and follower are able to assess their decisions based on methodically generated data and, unlike other PSE literature approaches, taking into consideration the variability between generated profits scenarios.

Finally, the proposed decision support procedures enable the decentralized SCs organizations to modify their relationships during the optimization procedure, which can be used for further second-stage agreements. Furthermore, the proposed generic models are flexible enough to be applied in practice to real cases, including simple/global SCs centralized/decentralized, as illustrated in the presented case study.

\section{Acknowledgement}

Financial support received from the "Agència de Gestió d'Ajuts Universitaris i de Recerca AGAUR", the Spanish Ministry of Economy and Competitiveness and the European Regional Development Fund, both funding the Project SIGERA (DPI2012-37154-C02-01), and from the Generalitat de Catalunya (2014-SGR-1092-CEPEiMA), is fully appreciated. 


\section{Acronyms}

$\begin{array}{ll}\text { CNS } & \text { Cooperative-Negotiation Scenario } \\ \text { CPU } & \text { Central Processing Unit } \\ \text { EWO } & \text { Enterprise-Wide Optimization } \\ \text { GAMS } & \text { The General Algebraic Modeling System } \\ \text { GHz } & \text { Gigahertz } \\ \text { GloMIQO } & \text { Global Mixed-Integer Quadratic Optimizer } \\ \text { GT } & \text { Game Theory } \\ \text { LP } & \text { Linear Programming } \\ \text { MINLP } & \text { Mixed Integer Non-Linear Programming } \\ \text { MILP } & \text { Mixed Integer Linear Programming } \\ \text { MW } & \text { Megawatt } \\ \text { nCNS } & \text { Non-Cooperative-Negotiation Scenario } \\ \text { NE } & \text { Nash Equilibrium } \\ \text { NLP } & \text { Non-Linear Programming } \\ \text { PMAGA } & \text { Pinch Multi-Agent Genetic Algorithm } \\ \text { PSE } & \text { Process System Engineering } \\ \text { RM } & \text { Raw Material } \\ \text { SBDN } & \text { Scenario-Based Dynamic Negotiations } \\ \text { SC } & \text { Supply Chain } \\ \text { SCM } & \text { Supply Chain Management } \\ \text { SS } & \text { Standalone Scenario } \\ \mu & \text { Mean } \\ \sigma & \text { Standard deviation }\end{array}$

\section{Nomenclature}

\section{Indexes}

$D$

$M$

$N$

$P L$

$R$

$S C$

$T$

W

\section{Sets}

F

$L$

$m$

$n$ $3^{\text {rd }}$ party

Final customers

number of Piecewise price and quantity zones of $3^{\text {rd }}$ parties

Production plant

resource (raw materials, intermediate/final products, energy,...)

supply chain

time period

warehouse

follower SC

leader SC

final consumers

piecewise pricing zone of $3^{\text {rd }}$ parties 


$\begin{array}{ll}p l & \text { production plants } \\ r & \text { resources (raw materials, intermediate/final products, energy,...) } \\ r^{\prime} & \text { negotiation resource (inner component, product, etc.) } \\ s & \text { external resources (RM, energy, etc.) suppliers } \\ S C & \text { supply chain } \\ t & \text { time periods } \\ w & \text { warehouses/distribution center } \\ w^{\prime} & \text { external warehouses/distribution centers } \\ x C & \text { external clients, follower SC } \\ x V & \text { external vendors, leader SC }\end{array}$

\section{Parameters}

$C_{r^{\prime}, S C^{\prime}, x c, t, n-1}^{\min }$

$C_{r^{\prime}, s c^{\prime}, x c, t, n}^{\max }$

$\operatorname{disI}_{r^{\prime}, s c^{\prime}}$

$\operatorname{dis}_{r, s c}$

$\operatorname{dis}_{r, s c}$

$f_{r, r^{\prime}, s c^{\prime}}$

$p c_{r^{\prime}, x c, t, n}^{\min }$

$p c_{r^{\prime}, x c, t, n-1}^{\max }$

$P R D_{r, p l, s c, t}^{\min }$

$P R D_{r, p l, s c, t}^{\max }$

$p v_{r^{\prime}, x v, t, n^{\prime}}^{\min }$

$p v_{r^{\prime}, x v, t, n^{\prime}}^{\max }$

$r p_{r, s c, m}$

$S T_{r, w, s c, t}^{\min }$

$S T_{r, w, S c, t}^{\max }$

$\operatorname{Sup}_{r, s, s c, n ", t}^{\min }$

$S u p_{r, s, s c, n ", t}^{\max }$

$V_{r^{\prime}, x V, s c^{\prime}, n^{\prime}, t}^{\min }$

minimum amount of resource $r^{\prime}$ from $s c^{\prime}$ (follower) to $3^{\text {rd }}$ party (external client $x c$ ), piecewise pricing zone $n-1$, time $t$

maximum amount of resource $r^{\prime}$ from $s c^{\prime}$ (follower) to $3^{\text {rd }}$ party (external client $x c$ ),

piecewise pricing zone $n$, time $t$

travel distance of resource $r^{\prime}$

travel distance of resource r (intermediate/final product,...)

travel distance of resource $r(R M$, energy,...)

production factor: quantity of resource r required to produce resource $r^{\prime}$ in sc

minimum unit price of resource $r^{\prime}$ at $3^{\text {rd }}$ party (external client $x c$ ), piecewise pricing zone $n$, time $t$

maximum unit price of resource $r^{\prime}$ at $3^{\text {rd }}$ party (external client $x c$ ), piecewise pricing zone $n-1$, time $t$

minimum production capacity of production plant pl in sc, time $t$

maximum production capacity of production plant pl in sc, time $t$

minimum unit price of resource $r^{\prime}$ at $3^{\text {rd }}$ party (external vendor $\mathrm{xv}$ ), piecewise pricing zone n', time $t$

maximum unit price of resource $r^{\prime}$ at $3^{\text {rd }}$ party (external vendor $\mathrm{xv}$ ), piecewise pricing zone $n^{\prime}$, time $t$

unit retail price of resource r of sc to $3^{\text {rd }}$ party ( final customer $m$ )

minimum storage capacity of resource $r$ at warehouse $w$ in $s c$, time $t$

maximum storage capacity of resource $r$ at warehouse $w$ in sc, time $t$

minimum external resource (RM, energy, ...) supplying capacity at $3^{\text {rd }}$ party (supplier s) to $s c$, piecewise pricing zone $n^{\prime \prime}$, time $t$

maximum external resource (RM, energy, ...) supplying capacity at $3^{\text {rd }}$ party (supplier s) to $s c$, piecewise pricing zone $n^{\prime \prime}$, time $t$

minimum amount of resource $r^{\prime}$ purchased from $3^{\text {rd }}$ party (external vendor $\mathrm{x} v$ ) by $s c^{\prime}$ (leader), piecewise pricing zone n', time $t$ 


$$
\begin{aligned}
& V_{r^{\prime}, x v, s c^{\prime}, n^{\prime}, t}^{\max } \\
& \operatorname{vrm}_{r, s, s c, n^{\prime \prime, t}}^{\min } \\
& \operatorname{vrm}_{r, s, s c, n^{\prime \prime, t}}^{\max } \\
& u_{p r d f_{r^{\prime}, s c^{\prime}}} \\
& \text { uprd }_{r, s c} \\
& \text { ustr }_{r, w, s c} \\
& \text { ust }_{r^{\prime}, w, s c^{\prime}} \\
& \text { utrs }_{r, s c} \\
& \text { utrm }_{r, s c} \\
& \text { utrI }_{r ', s c^{\prime}}
\end{aligned}
$$

\section{Variables:}

$$
\begin{aligned}
& C_{r^{\prime}, w, s c^{\prime}, x c, t} \\
& C_{r^{\prime}, s c^{\prime}, x c, t} \\
& C_{r^{\prime}, s c^{\prime}, x c, n, t}
\end{aligned}
$$

$\operatorname{COST}_{\text {sc }}$

$C P R_{\text {sc }}$

$$
C R M_{\text {sc }}
$$$$
\mathrm{CST}_{\text {sc }}
$$

$\mathrm{CTR}_{\mathrm{SC}}$

ExPROF ${ }_{s c^{\prime}}$

$$
\text { FPRD }_{r, r^{\prime}, p l, s c^{\prime}, t}
$$$$
\operatorname{LPRD}_{r^{\prime}, r, p l, s c^{\prime}, t}
$$$$
M K_{r, w, s c, m, t}
$$$$
p_{r^{\prime}, s c^{\prime}}
$$$$
p_{r^{\prime}, s c^{\prime}}^{\text {contract }}
$$

$p c_{r^{\prime}, x c, t}$

$p c_{r^{\prime}, x c, t, n}$

$P_{R, p l, s c, t}$ maximum amount of resource $r^{\prime}$ purchased from $3^{\text {rd }}$ party (external vendor $x \mathrm{v}$ ) by sc' (leader), piecewise pricing zone $n^{\prime}$, time $t$

minimum external resource (RM, energy, ...) unit price at $3^{\text {rd }}$ party (supplier s) to $S C$, piecewise pricing zone $n^{\prime \prime}$, time $t$

maximum external resource (RM, energy, ...) unit price at $3^{\text {rd }}$ party (supplier s) to sc, piecewise pricing zone $n$ ", time $t$

unit production cost value of resource $r^{\prime}$ in $s c^{\prime}$ (follower)

unit production cost value to produce resource $r$ in sc

unit storage cost value of resource $r$ in warehouse $w$ at sc

unit storage cost value of resource $r^{\prime}$ in warehouse $w$ at sc

unit transport cost value of resource $r(R M$, energy,...)

unit transport cost value of resource $r$ (intermediate/final product,...)

unit transport cost value of resource $r^{\prime}$

resources $r^{\prime}$ from warehouse $w$ of $s c^{\prime}$ (follower) to $3^{\text {rd }}$ party (external client $x c$ ), time $t$ total quantity of resource $r^{\prime}$ from $s c^{\prime}$ (follower) to $3^{\text {rd }}$ party (external client $x c$ ), time $t$ total quantity of resource $r^{\prime}$ from $s c^{\prime}$ (follower) to $3^{\text {rd }}$ party (external client $x c$ ), piecewise pricing zone $n$, time $t$

Cost of supply chain sc

production cost of $S C$

External resources (RM, energy, ...) cost of sc

storage cost of $S C$

transport cost of SC

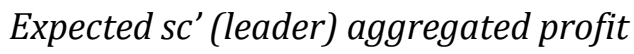

production levels of resource $r^{\prime}$ from resource $r$ in production plant pl of sc' (follower), time $t$

production of resource $r$ (intermediate/final product, energy, etc.) from resource $r^{\prime}$ at production plant $\mathrm{pl}$ of $\mathrm{sc}^{\prime}$ (leader), time $t$

resources $r$ flows from warehouse $w$ of sc to $3^{\text {rd }}$ party (final customer $m$ )

unit transfer price of resource $r^{\prime}$ at $s c^{\prime}$

coordination/collaboration contract quantity of $r^{\prime}$, time $t$

unit price of resource $r^{\prime}$ at $3^{\text {rd }}$ party (external client $x c$ ), time $t$

unit price of resource $r^{\prime}$ at $3^{\text {rd }}$ party (external client $x c$ ), piecewise pricing zone $n$, time $t$ production of resource $r$ at production plant $\mathrm{pl}$ of $s c$, time $t$ 
$P R O F_{s c}$

prob $_{\text {sc' }}$

$p v_{r^{\prime}, x v, t}$

$Q_{r^{\prime}, s c^{\prime}, t}$

$Q_{r^{\prime}, w, s c^{\prime}, w^{\prime}, t}$

$Q_{r^{\prime}, w^{\prime}, w, s c^{\prime}, t}$

$Q L_{r^{\prime}, p l, t}$

$Q_{r^{\prime}, s c, t}^{\text {contract }}$

$S A L E_{s c}$

$S T_{r^{\prime}, w, s c, t}$

$S T_{r^{\prime}, w, s c, t-1}$

$S T R_{r, w, s c, t}$

$\operatorname{Sup}_{r, s, s c, t}$

Tprofit

$V_{r^{\prime}, x v, w, s c, t}$

$v_{r m}, s, t$

$X_{r, x c, t, n}$ aggregated profit of supply chain sc

probability of acceptance

unit price resource $r^{\prime}$ at external vendor $\mathrm{x}$, time $t$

quantity of resource $r^{\prime}$ in sc', time $t$

quantity of resource r' from warehouses $w$ (follower)to warehouse w'(leader)

quantity of resource $r^{\prime}$ from warehouses $w^{\prime}$ (follower) warehouse $w$ (leader), time $t$

quantity of resource $r^{\prime}$ demanded by manufacturing plants pl' (leader), time $t$

coordination/collaboration contract unit price of $r$, time $t$

economic incomes (sales value) of supply chain sc

storage of $r^{\prime}$ at warehouse $w$ of $s c$, time $t$

storage of $r^{\prime}$ at warehouse $w$ of sc, time $t-1$

Storage of resource $r$ (final product, energy, ...) in warehouse $w$ at sc, time $t$

resource $r$ from $3^{\text {rd }}$ party (supplier s) to sc, time $t$

aggregated profit of the whole system

resource $r^{\prime}$ from $3^{\text {rd }}$ party (external vendor $x v$ ) to warehouse $w$ of sc (leader), time $t$ external resources (RM, energy, ...) unit value

binary variables 


\section{References}

Amaro A, Barbosa-Póvoa A. Supply Chain Management-Optimal Tactical for Sustainable Products' Portfolio. Computer Aided Chemical Engineering 2013; 32: 559-564.

Banaszewski RF, Arruda LV, Simão JM, Tacla CA, Barbosa-Póvoa AP, Relvas S An application of a multiagent auction-based protocol to the tactical tactical of oil product transport in the Brazilian multimodal network. Computers and Chemical Engineering 2013;59:17- 32.

Cachon GP. Supply chain coordination with contracts. Chapter 6 in: de Kok, A.G., Graves, S.C., Supply Chain Management: Strategic, Coordination and Operation. Elsevier, North-Holland 2003: 978-0-44451328-1.

Cao K, Feng X, Ma H. Pinch multi-agent genetic algorithm for optimizing water-using networks. Computers \& Chemical Engineering 2007; 31:1565-1575.

Cao E, Wan C, Lai M. Coordination of a supply chain with one manufacturer and multiple competing retailers under simultaneous demand and cost disruptions. Int. J. Prod Econ 2013, 141,425-433.

Colson B, Marcotte P, Savard G.. An overview of bilevel optimization. Ann Oper Res 2007; 153: 235-56.

Grossmann IE. Challenges in the new millennium: product discovery and design, enterprise and supply chain optimization, global life cycle assessment. Computers \& Chemical Engineering 2004; 29:29-39.

Hennet JC, \& Arda Y. Supply chain coordination: A game-theory approach. Eng. Applications of Artificial Intelligence 2008; 21:399-405.

Hjaila K, Laínez-Aguirre J.M., Zamarripa M, Puigjaner L. and Espuña A. Optimal integration of thirdparties in a coordinated supply chain management environment, Computers and Chemical Engineering 2016 ; $86: 48-61$.

Hjaila K, Laínez-Aguirre JM, Puigjaner L, Espuña A. Decentralized manufacturing supply chains coordination under uncertain competitiveness. Procedia Eng 2015; 132:942-9.

Laínez JM, Kopanos G, Espuña A, Puigjaner L. Flexible Strategic-Tactical of Supply Chain Networks. American Institute of Chemical Engineers AIChE Journal 2009 1736-1753.

Laínez JM, Guillén-Gosálbez G, Badell M, Espuña A, Puigjaner L. Enhancing corporate value in the optimal design of chemical supply chains. Ind Eng Chem Res 2007; 46(23): 7739-57.

Li X, Li Y, Cai X. Double marginalization and coordination in the supply chain with uncertain supply. European Journal of Operational Research 2013; 226: 228-236.

Misener R. and Floudas C. GloMIQO: Global mixed-integer quadratic optimizer. J Glob Optim 2013; 57: $3-50$.

Ministry of Industry, Energy and Tourism, 2015. http://www.minetur.gob.es/energia/esES/Paginas/index.aspx 
Yue D, and You F. Game-Theoretic Modeling and Optimization of Multi-echelon Supply Chain Strategic and Operation under Stackelberg Game and Market Equilibrium. Computers and Chemical Engineering $2014 ; 71: 347-361$.

Zamarripa M, Hjaila K, Silvente J, Espuña A. Tactical management for coordinated supply chains. Computers \& Chemical Engineering 2014; 66: 110-123.

Zhao Y, Wang S, Cheng, TCE, Yang X, Huang Z. Coordination of supply chains by option contracts: A cooperative game theory approach. European J. of Operational Research 2010; 207: 668-675.

Zhao Y, Ma L, Xie G, Cheng TCE. Coordination of supply chains with bidirectional option contracts. European Journal of Operational Research 2013; 229: 375-381.

Zeballos LJ, Méndez CA, Barbosa-Povoa AP, Novais AQ. Multi-period strategic and tactical of closed-loop supply chains with uncertain supply and demand. Computers and Chemical Engineering 2014; 66: 151164. 